\title{
- PRACTLAL.
}

-RABBIT • KE PPINC.

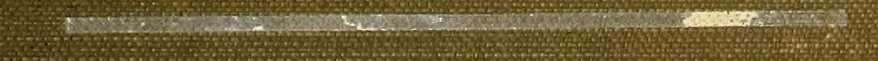

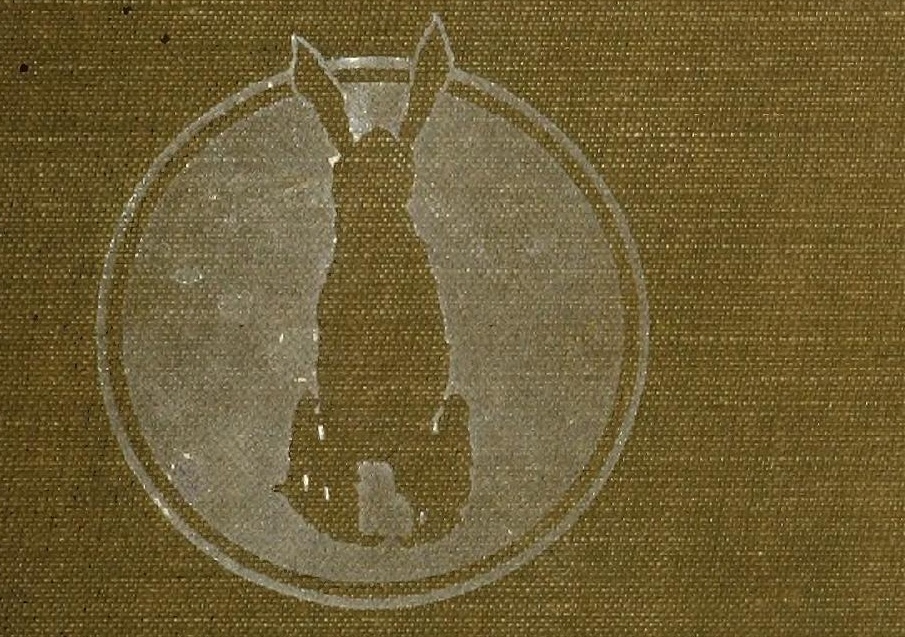

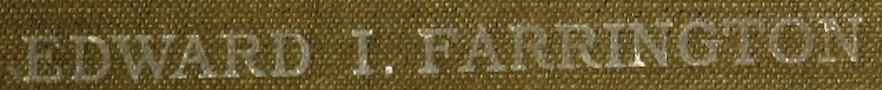




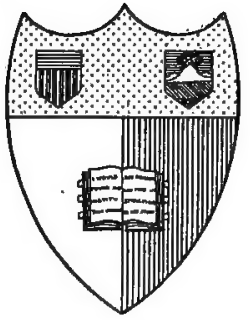

\section{Aivu 其utk \\ State (4allege of Agriculture \\ Xt Crarnell Hninergity \\ Jthata, ㅊ. 䍿.}

\section{Iithrary}




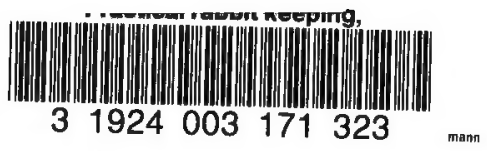




\section{Cornell University Library}

The original of this book is in the Cornell University Library.

There are no known copyright restrictions in the United States on the use of the text. 


\section{PRACTICAL RABBIT KEEPING}






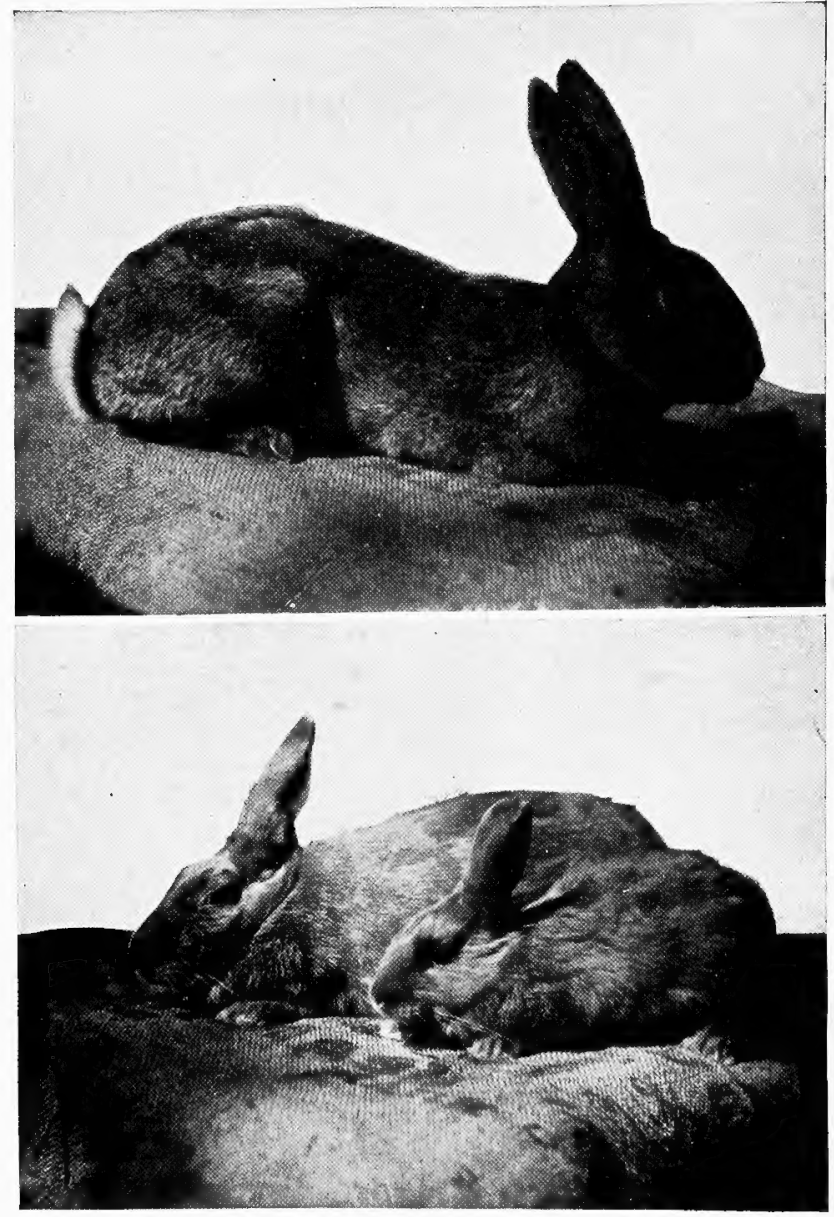

(above) Young Belgian Hare Buck (below) Mother and Daughter-Blue Imperials 


\section{PRACTICAL}

RABBIT

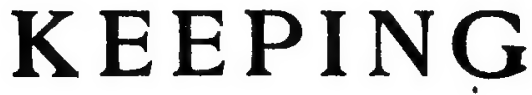

BY

\section{EDWARD I. FARRINGTON} Author of "The Home Poultry Book."

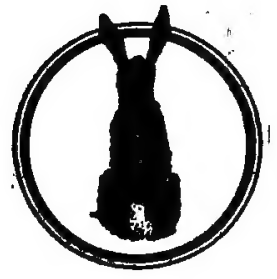

NEW YORK

ROBERT M. McBRIDE \& CO. 1919 
Copyright, r9r9

by

ROBERT M. McBRIDE \& COMPANY

Prinsed in the United States of Amerrec.

(Second Printing August, 1919)

$\overline{\text { Published June, } 1919}$ 


\section{CONTENTS}

CHAPTER

PAGE

I Why to Raise Rabits. . . . . I

II A Little Rabiit History • • . . 9

III The Best Rabbits For Meat • • • I6

IV The So-called Fancy Rabbits . • . 24

V Rabbits as Pets For Children . . . 4 I

VI How to Begin Rabitit Keeping • • . 46

VII Houses, Hutches and Yards • • 55

VIII The G̈eneral Care of Rabbits • • • 74

iX What and How to Feed . . . . 80

X Simple Rules For Breeding • • • 96

XI Raising the Young Stock . . . . IIo

XII Exhibiting and Selling • • • • II5

XIII Preparing Rabbits For the Table . . I25

XIV Rabbit Furs and Their Value . • • I36

XV When Rabbits Are Out of Condition. 146

APPENDIX . . . . . . . I53

INDEX . . . . . . . 167 



\section{THE ILLUSTRATIONS}

Young Belgian Hare Buck

Mother and Daughter-

Blue Imperials

Pair of Young Himalayans

An English Rabbit . . . . . " " 24

White Giant and Her Offspring . . " " 40

So-called Black Siberian Doe . . . " " 40

Well-arranged Commercial Rabbitry . " " 56

Type of Convenient Outdoor Hutch . " " " 72

Well-marked Dutch Rabbit . . . " " I20

English Lop-eared Rabbit . . " " 120

Hutches in Three Tiers . . . . " " 136

The Right Way to Lift a Rabbit . " " $\quad 152$

Register Number Tatooed on Ear . " $\quad$ " 152 



\title{
PRACTICAL RABBIT KEEPING
}

\author{
Chapter I. \\ WHY TO RAISE RABBITS.
}

OME twenty years ago the United States and Canada experienced what is still spoken of as the Belgian Hare boom. Small fortunes were made and lost in the breeding of these rabbits-for true rabbits they are, the name of hare being a misnomer. Elaborate breeding houses were constructed, hundreds of animals were imported and such prices as fifty and one hundred dollars for single rabbits were common. Now this boom was largely artificial, built up by a few breeders with stock to sell and kept going by the repeated assurances of these breeders that all surplus stock could be sold for meat at profitable prices. In point of fact there was very little demand for rabbit meat apart from that 


\section{PRACTICAL RABBIT KEEPING}

of wild rabbits, large numbers of which are always offered every winter. When this was discovered the bottom dropped out of the boom and rabbits which had been worth fifty dollars one day were worth hardly five the next. The public was not ready for rabbit meat as a steady diet at that time, as other kinds of meat, including poultry, were comparatively cheap and plentiful.

Nevertheless, a large number of people continued to keep rabbits in a small way, some of them because they had become fond of the meat and found they could produce it at very low cost, and others because they enjoyed making pets of the handsome little animals. Now another and healthier development of the industry is being felt all over the land, fostered to a great extent by the high cost of living. Rabbit meat is the cheapest meat that can be raised, not excepting poultry. It is meat of excellent quality, too, and can be prepared for the table in many ways.

Many of the advertisements in regard to the remarkable fecundity of the rabbit are misleading yet it is a fact that the animals multiply very rapidly. A doe can have five litters 
a year without draining her vitality and she may be fairly expected to raise six youngsters from each litter, which makes a total of thirty. This may be done when starting with only a single animal, the doe being purchased after having been bred.

The cost of raising the young rabbits will vary with the location and amount of food purchased. Six cents a pound is often set down as an average. Many breeders claim that they get their rabbits to market size for several cents less per pound, and if they have a garden doubtless they do, as much of the food eaten by the animals can be raised at home. It has been estimated that the cost of maintaining a mature rabbit for a year when all the food must be purchased is about one dollar. The majority of amateur rabbit keepers have a little land and expect to feed their animals largely on garden stuff, in winter as well as in summer, carrots, parsnips and other vegetables which can be stored for winter use being grown.

Less space is required for rabbits than for chickens, and if they are kept in hutches, they will not occupy ground needed for growing 


\section{PRACTICAL RABBIT KEEPING}

crops. Rabbits demand but comparatively little care, although they must be kept clean and fed regularly. At present there is a considerable demand for breeding stock in most communities, it being possible to sell a sufficient number of breeders to pay all the cost of raising the rabbit meat consumed on the table. Indeed, many breeders have only the poorest specimens left for food, but this situation cannot be expected to last and the industry must eventually become established on a meat basis.

Across the water an enormous demand for rabbit meat has been created by the war. Even before the war came Great Britain imported Io,000 or I 2,000 tons. When the supply from the continent failed and shipments from Australia were cut off for lack of ships, the English people began raising their own rabbits and rabbit hutches were to be found in back yards everywhere. Now the business of raising rabbits for food seems to have been established on a permanent basis in England, as it has been on the continent for many years. The extent to which interest in rabbit keeping has spread throughout the United States and Canada may be judged by visiting the shows, 


\section{WHY TO RAISE RABBITS}

where hundreds of animals are entered and where instruction in preparing them for the table is given. More advertisements are appearing in the papers than ever before, more commercial rabbits are being seen in the markets and more are served in restaurants and hotels. The industry has persisted to a greater degree in California than anywhere else, but rabbit keeping has become common everywhere and some large plants have been established.

In past years immense quantities of rabbit fur have been imported from Australia by hat makers and a considerable number of skins have been brought in by furriers. It has been difficult to get these people interested in American offerings because no large amounts could be purchased in single lots. American skins are being bought to an increasing extent, however, and this branch of the business has much promise. When an amateur rabbit keeper has only a few pelts he can tan them and have them made up into furs for his own family.

All this applies to the utility side of rabbit keeping, and that is the side which interests 


\section{PRACTICAL RABBIT KEEPING}

the average beginner. There is another side, however, which is called the fancy, that being rather a poor name for the keeping of rabbits for pleasure and for exhibition. Fanciers are much more numerous than is commonly realized, many professional and business men as well as working men keeping a few fine animals for recreation and amusement. The breeds usually kept for utility purposes are Belgian hares, Giant rabbits of different kinds and New Zealand Reds. Fanciers, however, find many other breeds to choose from, some of them like the Lop Eared Rabbits and the Angoras requiring very careful handling. Fanciers naturally charge much more for their animals, if the stock is good, than do breeders who confine themselves to utility rabbits. An animal that can win at a show is highly prized. Competition at many of the shows is very keen and the greatest skill must be exercised to produce winners. It is a form of recreation in which great delight is taken. The breeders of different kinds of rabbits have their associations and enjoy getting together to talk over the ins and outs of the game. 
Naturally enough many fanciers also sell utility rabbits and food animals, especially if they happen to be breeders of Belgian hares, Giants or New Zealands. Only a few of all those raised will be of the highest type and some outlet for the culls is needed. It often happens that breeders who start with utility stock and no high aspirations eventually become ardent fanciers. This is a fascinating side of rabbit keeping and is appealing to an increasingly large number of men, especially as speculators and dishonest breeders are being curbed and opportunities for redress presented through the medium of a national association.

Finally there is the keeping of rabbits for pets by children. Pet rabbits have been popular with boys from a time which extends much farther back than the oldest of us can remember. The rabbits most often seen are little pink-eyed white creatures which all too often move along to the rabbit Heaven in a very short time. If your boy wants to keep rabbits get him some other kind, for these have many faults and few virtues. Belgian Hares, Dutch rabbits, New Zealand Reds, Checkered Giants, and Himalayans will be found 


\section{PRACTICAL RABBIT KEEPING}

much more satisfactory. Many boys and some girls are able to make considerable money by selling rabbits, and there are few animals which make better pets. 


\section{Chapter II.}

\section{A LITTLE RABBIT HISTORY}

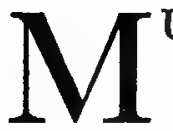

$\mathrm{UCH}$ confusion is encountered when we undertake to trace the history of the Belgian hare, and many of the other popular breeds. In the first place, the Belgian hare and the other so-called hares in captivity are not hares at all, but true rabbits. Real hares are not easily domesticated, and would be of little value in any event. The Belgian hare probably was given that name because in alert expression and general appearance it somewhat suggested the wild hare. The differences between hares and rabbits are so marked that there is no ground for a mistake. Hares are born with their eyes open and covered with fur. In a very short time they are running about. Rabbits, on the other hand, are born blind and naked. They remain perfectly helpless for some days, and it is several weeks before they become active. 


\section{Io PRACTICAL RABBIT KEEPING}

Probably all the fancy rabbits are descended from the common wild rabbit (Lepus Cuniculus). That this is true seems demonstrated by the fact, as pointed out by an English authority, C. J. Davies, that reversion on crossing is always to the wild color, that all varieties cross freely and the progeny are fertile together or with either parent, and that wild rabbits can be reared and crossed with tame rabbits.

Very ancient history contained mention of domestic rabbits. They seem to have been known in China for several centuries B. C.

Some new breeds have come into being in a haphazard way, while others have been deliberately made. The English fanciers are responsible for three or four distinct breeds, some of them produced from native animals, although there is reason to believe that at least a little outside blood was introduced in most cases. The large Lop-eared rabbit is supposed to be wholly an English creation. The English breeders have been especially concerned with fancy stock. On the continent, on the other hand, more attention has been given to the production of utility rabbits, especially 
those capable of producing high class fur. The Argent de Champagne is one of the best examples of what the French have done in this direction. The fur of this rabbit is of such excellent quality that large quantities were being shipped to other countries before the war broke out. Probably this industry will be quickly built up again. Certainly rabbits are having an important place in the rehabilitation of France and Belgium.

While hares seem to stand the very cold climates, rabbits, as a rule, thrive best in the warmer countries. Most kinds, though, can be gradually inured to very cold weather. Thousands of rabbits have been raised in the European countries to one in the United States and Canada. At least this was the case up to a very few years ago, and until the high price of meat began to stimulate interest in a source which promised to help in cutting the high cost of living. The peoples of Europe have found meat much less plentiful than those of this country, and accordingly have been compelled to the cultivation of rabbit keeping on an extensive scale. It is said that England uses from twenty-five to thirty million pounds 
of rabbit meat every year. In France, Belgium and Germany, rabbits are eaten everywhere as a matter of course. When English people talk about rabbits they often use the old name, coney, which has been applied by furriers to certain skins.

The origin of some of the fancy rabbits is fairly well known. The Flemish Giant, for example, is a native of Belgium or Flanders, from which place it found its way into other parts of Europe. Since the organization of a Flemish Giant club in England, it has been greatly improved, but the blood of other breeds has been introduced to some extent, which accounts for the many different colored specimens found. Occasionally, with the newer breeds, new classes must be eštablished by the standard makers. This has been so in the case of the Gray Flemish, which will now be given a separate place.

The exact origin of the Belgian hare has been the subject of controversy for many years, and sometimes this controversy has waxed decidedly warm. That it actually originated in Belgium nobody can positively say. Some breeders have gone so far as to claim 


\section{A LITTLE RABBIT HISTORY I3}

that it came from India. For a while it was considered necessary in this country to call it the Belgian hare rabbit, although, of course, that was a ridiculous mixture of names. The idea was to have people realize that it was really a rabbit. It does not owe all of its improved color to English breeders, for much has been done in this country in the last twenty years. The original color probably was a common gray. There is reason to believe that the Belgian hare and the Flemish Giant are both descendants of the old Patagonian rabbit, and the difference in coloring as well as in size is due solely to the manner in which the two lines have been handled.

Sometimes the name of a rabbit is a fairly safe index as to its origin. Thus the Himalayan rabbit probably came from the Himalaya Mountains. It has long been a popular rabbit on the continent, being raised largely for its fur, which when properly cured resembles ermine.

The English rabbit, too, is correctly named. The popular theory is that it is an outgrowth of the common English rabbit. It is a very hard rabbit to breed to perfection, and that 


\section{I4 PRACTICAL RABBIT KEEPING}

probably is one reason why it is so little known in America. The finest specimens in the country are being produced by breeders in Massachusetts, New York and New Jersey.

Coming to the breed which it so very much resembles, the American Spotted Giant, we find serious difficulty in determining its ancestry. It was formerly known as the German Checkered Giant, but when the world war put a ban on everything German, its name was changed by popular approval to American Spotted Giant. This seems to have been a perfectly safe thing to do, for there is no good evidence to show that Germany had anything to do with its origin. It has been found of late years that German names have been tacked to a great many things to which it had no claim.

Dutch rabbits are better known than many other kinds, and their name seems to be justified. At least they have been bred in Holland for a long time, and have been used there for meat, although in this country they are con. sidered strictly a fancy rabbit. Some breeders use them as nurse does as they are excellent milkers and mothers. 
A LITTLE RABBIT HISTORY I5

Lop-eared rabbits are most commonly considered as English creations. There is, however, a French lop-eared rabbit also, but it is smaller both in body and in the size of its ears. The English lop-eared rabbit seems to be all English, and distinctly a manufactured breed. Angora rabbits came probably from Persia, where long-haired creatures seem to have been more common than in most places, the Persian cat being another example. Angoras are often used for food in parts of Europe, but in this country it is difficult to get people to eat them.

In the New Zealand Red, a rabbit the popularity of which is carrying it all over the country, we have a puzzle. The claim is made that it was introduced from New Zealand some years ago, a few specimens being taken to California by sailors. No real verification of this claim has been made, or seems likely to be. As no better way of accounting for the New Zealand Red can be thought of, however, we may as well consider it to be properly named. At least, attempts to drop the word, New Zealand, have been failures. At any rate, it has taken the Pacific coast almost by storm. 


\section{Chapter III.}

\section{THE BEST RABBITS FOR MEAT}

7 HE meat of practically all rabbits is suitable for food. Yet only a few kinds

1 can be raised profitably. Moreover, there is a general disinclination to the use of the common white rabbits on the table. These rabbits are said to have flesh which is too sweet to be very palatable, but in any event, they are not commonly included among the utility animals. Europe has rather a long list of breeds considered to be valuable for food, but breeders in the United States and Canada confine themselves chiefly to Belgian hares, Flemish Giants and New Zealand Reds. There are various kinds of giant rabbits which might be used for food if plentiful enough, but the common Flemish Giant is the one usually set down as the meat rabbit.

The Belgian hare is by all means the best known and the most widely raised. It is a 
very prolific rabbit, and the meat is of high quality. Many breeders, however, prefer the Flemish Giant because of its large size. Specimens weighing ten pounds are common, and occasionally one nearly twice that weight is found. 'As Belgian hares run only from six to eight pounds, considerable more meat is obtained from the Giant. On the other hand, the meat of these big rabbits is coarser than that of the smaller Belgian, and the flavor is not considered quite so good, except, of course, by breeders of Flemish Giants, who often claim it to be equal to any other breed known. Then the Flemish Giant grows more slowly, not being mature until it is fourteen or fifteen months old. They make the best eating at about five months. Judge Chas. L. Gibson says that the Steel Gray Flemish Giant is the most popular rabbit in America today.

For a long time only these two breeds were offered in the general market. Of late years, however, a breed known as the New Zealand Red has won extreme popularity on the Pacific coast, and is rapidly coming into favor among eastern breeders. This rabbit has some special merits, and may prove to be the best 


\section{I8 PRACTICAL RABBIT KEEPING}

commercial sort yet raised in this country. In spite of their usefulness it is an admitted fact that both the Belgian hare and the Flemish Giant are hearty eaters, and that there is a large amount of waste when they are dressed for the table. Many English breeders candidly admit these facts, and say that some other breeds are more profitable. It is claimed for the New Zealand Red that it consumes less food than even the Belgian, which because of its smaller size eats much less than the Flemish Giant.

When dressed for the table, the New Zealand Red weighs about two pounds more than the Belgian, and the meat is just as finegrained, palatable and nutritious. In parts of California the New Zealand Red is about the only rabbit seen. It is also raised extensively in the other Pacific coast states, many breeders having adopted it in place of Belgians and Giants. It seems to be perfectly hardy in any part of the continent, although just how the eastern climate will eventually act upon it remains to be seen. Apparently it is a little more difficult to get large specimens east of the Rockies than it is on the Pacific coast. 


\section{THE BEST RABBITS FOR MEAT I9}

Most rabbits are ready for the table when about four months old. Although Flemish Giants are slow to mature, they make excellent friers at the age of three months, but should be a little older for roasting. Rabbits can be eaten when only two months old. It is generally considered that all commercial rabbits are best for the table if killed before they are a year old. Nevertheless, rabbits two years old make very good eating. It is a common plan when raising rabbits commercially to keep a doe until the end of her second year, and then to market her, her place as breeder being taken by a younger doe. Usually the bucks are disposed of when young, except for a particularly good specimen, which is retained for breeding purposes. If rabbits are being raised for market it is always a good plan to castrate the young bucks, when they can be kept together with less fighting. Although two people are required the operation is easily performed after a little experience has been acquired.

Breeders are likely to make extravagant claims for the particular kind of rabbits which they happen to be raising, but the ama- 
teur can confidently begin with any of the breeds named. As he goes on, he probably will do a little experimenting, and may find that one particular kind will prove more profitable than any other. There is always the matter of one's market to be considered. In some places very large rabbits may be wanted, without much regard to quality, while in others small animals may be in demand. For home eating the writer's preference is for Belgian hares, probably because he has had more experience with them than with any other kind. There seems to be some evidence, though, to support the claim that New Zealand Reds are a little easier to raise. Very much depends upon the strain, whatever breed may be kept, just as with poultry. Some breeders are able to produce very much better stock than others. There has been careless inbreeding with Belgian hares; and so much attention has been given to producing show animals that many strains have low vitality, and give considerable trouble, except in the hands of experts. A good many breeders of New Zealands in the Eastern States find that they are especially susceptible to colds and 


\section{THE BEST RABBITS FOR MEAT 2i}

snuffles as they are not yet fully acclimated.

Breeding fancy rabbits is quite a different matter from breeding food rabbits. Fanciers naturally work for fine points, and favor their breeding animals. They may not try to raise more than two or three litters a year, and reduce these litters to the best specimens. The utility breeder, on the contrary, aims to produce as many animals as he can without drawing too heavily on the vitality of his stock. $\mathrm{He}$ will endeavor to get from four to six litters a year from each doe, and will expect her to raise six or seven youngsters. He will keep a limited number of bucks, say at the rate of one for each ten does. He will raise some specimens which a fancier would not want seen in his pens.

The man or woman who is keeping only a few rabbits for home use will perhaps keep no buck at all, but will have his or her does bred at the rabbitry or some neighbor's who has a larger stock. It is not economy to keep a buck which is going to be used only at long intervals.

Obviously every fancier will have many rabbits which are not good enough to be used 


\section{2 \\ PRACTICAL RABBIT KEEPING}

for show purposes or to sell for breeding purposes. He therefore has a certain number of animals to sell for food purposes, unless he is so devoid of honor as to palm off even his poor animals as desirable breeders, counting on the inexperience of beginners to make this possible.

There is a growing call for strictly utility animals, but it will pay even the amateur to keep the best breeding stock that he can get, providing it is not lacking in size or stamina, because he is almost certain to find a sale for well marked animals at a good price.

Yet it is because of their ability to supply a large amount of food cheaply that rabbits are being most vigorously exploited. The situation in England and on the continent, where meat is scarce, is reflected here. In Great Britain the Board of Agriculture has urged gardeners to raise rabbits for food, to take the place of beef and mutton. Three pounds of rabbit, the Board says, with one pound of bacon, will provide more nitrogenous and fatty food than four pounds of beef. Rabbit clubs are being formed in England. A nationwide rabbit breeding campaign is being car- 


\section{THE BEST RABBITS FOR MEAT 23}

ried on, it being realized that rabbits will meet the need for meat quicker than any other animals. There are a few places in the United States where breeding is being done extensively. Two or three years ago a rabbit farm was started at the Federal Penitentiary in Leavenworth, Kansas, to furnish meat for the hospital. About three acres were enclosed and stocked with a hundred does and a dozen bucks. There are large rabbit farms in California and rabbit meat canneries at Los Angeles and Hutchinson, Kansas.

In order to help eliminate the prejudice felt by many people against rabbit meat, a movement has been started to substitute the word venison and rabbit venison may become a common dish in restaurants all over the country. It is more important, though, to teach the consumer that the meat of the domesticated rabbit is very different from that of the common wild rabbit, great numbers of which are to be seen in many city markets in winter. The meat of domesticated rabbits is white, resembling the breast of chicken. It is sweet, fine grained, and the most nutritious flesh which can be obtained. 


\section{Chapter IV.}

\section{THE SO-CALLED FANCY RABBITS}

7 HERE are thousands of people who find their recreation in the raising of

1 fancy rabbits, meaning by this, rabbits of the show type. Several important exhibitions are held each year, attended by thousands of people. One of the biggest rabbit shows is held at Syracuse, N. Y., as a part of the New York State Fair. I: 1918 the entries at this show had increased to a thousand. Large shows are held in St. Louis, Boston, Chicago, and other cities, at which time the animals are judged and fanciers get together to talk over the merits of their pets.

Then, of course, hundreds of men and women breed high class rabbits purely for the pleasure they find in the work, and without any thought of showing them. It is by no means true, as is often supposed, that rabbit fanciers are confined to men. One of the lead- 


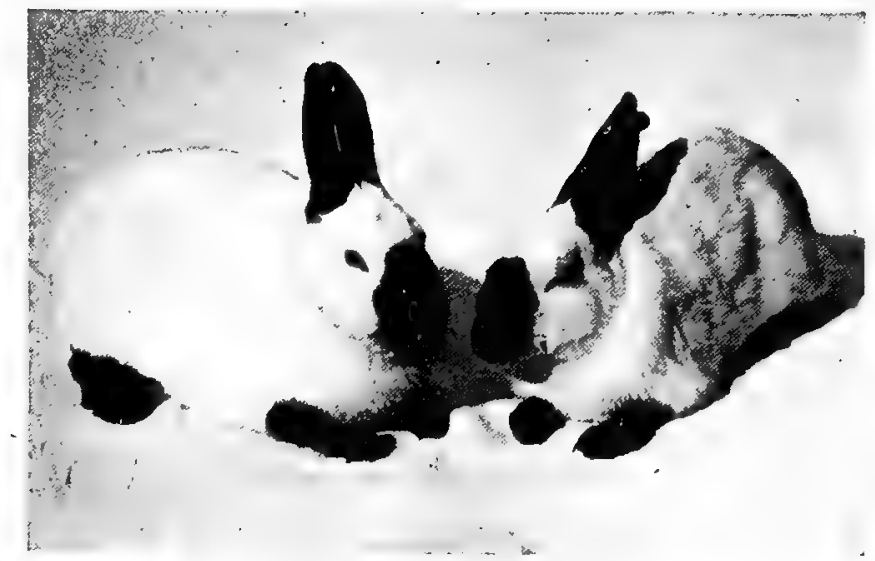

Pair of Young Himalayans 1 il

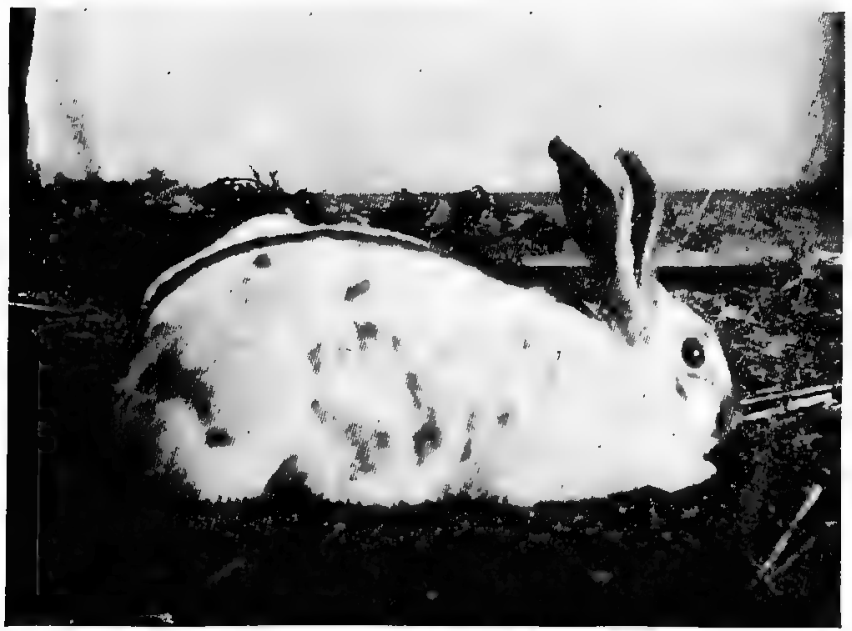

An English Rabbit 



\section{SO-CALLED FANCY RABBITS 25}

ing breeders in the eastern states is a woman who is reported to be a millionaire, and yet does much of the work of caring for her rabbits with her own hands. The list of exhibition or fancy rabbits includes all the breeds mentioned among the utility rabbits and many others in addition.

\section{The Belgian Hare}

Although a popular meat rabbit, probably the Belgian hare is also the favorite among fanciers, as it has been for many years. Few handsomer rabbits than well-bred Belgians can be found. Their long, slender bodies give them a peculiar racy appearance, and their mahogany-colored coats, with wide black lacings on the ears and wavy black ticking on the bodies, and their bright, alert expression create a tout-ensemble of more than ordinary beauty. It is difficult actually to describe the color of the Belgian. It is commonly stated to be Rufus red, but just what Rufus red is few people can really say. Perhaps the term "mahogany" indicates the proper color as well as any word. The ticking on the back 


\section{PRACTICAL RABBIT KEEPING}

differentiates it from any other red rabbit. Fineness of bone and refinement of contour are to be found in a worthy Belgian. There must be nothing coarse or heavy about the animal. Its head must be long, rather narrow, with well set ears about five inches long. The eye must be bright and sparkling. Someone has described the Belgian as having the same place among rabbits as a race horse among other equines. The color must extend to the feet, on which no sign of white should appear. The standard weight of the Belgian hare is eight pounds, but many smaller specimens are seen.

Whole books have been devoted to the Belgian hare alone, and anyone who takes this particular breed with the intention of producing show specimens should obtain all the literature on the subject which can be found.

\section{The Giant Class}

It may be assumed from its name that the Flemish Giant is a very large rabbit, in fact, the largest of all the breeds, ranging in weight all the way from ten to sixteen pounds. 


\section{SO-CALLED. FANCY RABBITS}

Heavier animals are often mentioned, but they are rare. Large size is the point aimed at with the Flemish Giant. It enjoys wide popularity, but is not so handsome a rabbit as the Belgian hare, although it has much the same origin. There are several distinct varieties, each of which has its connoisseurs. The exhibition Flemish Giant is steel-gray. It has been greatly improved through the work of fanciers in England and America. The latter country now produces quite as good animals as those formerly imported from across the water. Steel-gray Flemish bucks should not weigh less than twelve pounds, and does should weigh at least fourteen, if they are to be up to the standard. The body is much chunkier than that of the Belgian, and has a broad, powerful appearance. They do not grow so fast as the Belgians and other breeds, often not maturing until nearly fifteen months of age.

The Steel-gray Flemish gets its name from its color, which is carried all over its head, ears, body and feet, although as near white as possible under the belly and tail.

A separate class has been made for the Gray 
Flemish Giant, which is more nearly brown than steel-gray. Young animals are slow to get their true color. Black youngsters may make fine stock. The Black Flemish Giant corresponds to the other varieties except as to color.

There is considerable controversy in the United States and Canada over the question as to whether the so-called Black Siberian is a breed by itself or really a Black Flemish Giant. There seems to be a growing disposition to set it down under the latter head, although there are many breeders, especially in Canada and the central part of the United States, who are firmly convinced that the Black Siberian was brought to Canada from Russia several years ago, which accounts for its introduction to America. Perhaps the situation is still too confused for a satisfactory verdict to be rendered. At any rate, the Black Siberian and the Black Flemish Giant look about alike. They must be as free as possible from white hairs, and sometimes reach fourteen to fifteen pounds in weight. They seem likely to become particularly valuable for their fur. White Giants are little different, 


\section{SO-CALLED FANCY RABBITS 29}

except that they are pure white with pink eyes.

The American Spotted Giant is rapidly becoming a great favorite with fanciers. This rabbit was formerly known as the German Checkered Giant, but soon after the war broke out, that name was changed, with the approval of breeders the country over. In some markings this rabbit resembles the old English rabbit, but it is much larger. It has the same butterfly snout, to use the old expression for the odd black patch on the nose. It should have a line called the saddle running the length of the back. There are black circles around the eyes, the ears are black, and heavy patches of black are found on the hind quarters in place of the chain markings found on the English. Although black markings are most common, there are also Spotted Giants on which the color of the spots is blue, tortoise or gray. The standard calls for a weight of eleven pounds or more for bucks and thirteen or more for does. The body must be long and carried well off the ground. Animals of this breed are not quite so chunky in appearance as the Flemish Giants, but should have the same shape of head. 


\section{PRACTICAL RABBIT KEEPING}

Because of the remarkably handsome appearance made by the Spotted Giants, they seem likely to become one of the favorite rabbits of America. Considerable emphasis is being placed on the value of their skins, which make up into very attractive garments. For some years, this will doubtless be among the most profitable breeds to raise because of the great demand and the high prices being obtained. They must be bred carefully, though, if good specimens are to be obtained, and never bred when in the molt. Well marked specimens are hard to produce but are very valuable if they are also large in size.

\section{The English Rabbit}

The English rabbit which the American Spotted Giant so much resembles, is a very old breed, being a common rabbit in England before there was any well developed rabbit fancy. It is not to be classed among the Giants, weighing only about seven pounds when mature. Its markings are much like those already described for the American Spotted Giant, except that it should have a 


\section{SO-CALLED FANCY RABBITS 3 I}

well defined herring-bone line along the back. The spots on the sides are usually smaller and more widely distributed, forming what is commonly called a chain.

\section{The Dutch Rabbit}

Some description of the Dutch rabbits is given in the chapter on "Rabbits as Pets for Children." This breed has long had many admirers, and excellent specimens are being exhibited at all the shows. It is a small rabbit, the standard being five pounds and not over five and a half. The most common variety is black and white, but there are also blue and white, tortoise shell and white, and gray and white. The colors are solid in a good specimen, there being a perfect line of separation where the white appears. There is a white band around the body back of the head and including the forelegs and feet, the under jaw and the nose, running to a point between the ears. There should be about two inches of white on the feet and hind legs. The easiest way to make sure of good markings is to breed from stock that has gone through 


\section{PRACTICAL RABBIT KEEPING}

its second molt without deterioration in color.

\section{The English Lop-eared Rabbit}

For years past the lop-eared rabbit has been especially popular in England. It is bred to some extent in the United States and Canada, but requires warmer quarters and more careful attention than most of the other breeds. The one outstanding feature of this rabbit is its ears, which are of abnormal length. These ears are expected to reach twenty-four inches from the tip of one to the tip of the other, and often are longer. The width should be a quarter of the total, which would mean six inches for one ear when the extreme length measurement is two feet. Naturally the ears always hang at the side of the head. Different dark colors are found among the lop-ears. No success can be expected in breeding these animals unless they can be kept in heated quarters, and of course their hutches must be kept absolutely clean and the floor covered with bedding. Otherwise it would be impossible to keep the ears in proper shape, and no end of trouble would ensue. 


\section{SO-CALLED FANCY RABBITS 33}

\section{The Himalayan Rabbit}

Although bred to some extent in the United States and Canada for many years, the Himalayan rabbit seems to be winning unusual favor at the present time. This is not surprising, for it is among the most attractive of all breeds which the fancier has to choose from. Moreover, it becomes quite tame and seems to enjoy petting. Because of its curious markings, the Himalayan rabbit always makes a strong impression upon visitors to the shows. The body coat is pure white, while the ears, nose, tail and forefeet are either black or a deep chocolate color. The coat of this rabbit is especially soft and fine, giving it a neat, welldressed appearance. The eyes are pink, and the eye-lids often seem stained. This is a defect, but one which seems exceedingly difficult to eradicate. It is not a large rabbit, not being expected to weigh over five pounds.

In breeding the Himalayan several points must be remembered if good specimens are to be produced. If they are exposed to bright sunlight, the black hairs, curiously enough, begin to fade, and the color cannot readily be 


\section{PRACTICAL RABBIT KEEPING}

restored. On the other hand, a little sunlight seems desirable to make the color strong and shiny. With all rabbits that have pink eyes, however, it is necessary to avoid very brilliant sunlight. When Himalayans are born they are entirely white, a matter which often puzzles amateurs. After a month, however, the color begins to show, and gradually becomes stronger until the markings are complete at four months. It is of particular importance to keep the youngsters in dimly lighted quarters during the first five or six weeks of their lifetime.

\section{New Zealand Reds}

Any old-time rabbit breeder who has been out of the fancy for several years and visits a show today is immediately attracted by the large classes of New Zealand Reds, a breed of which he probably knew nothing. The New Zealand Red, after a highly successful career on the Pacific coast, has made its way eastward and is being taken up with enthusiasm by fanciers as well as by utility breeders in all sections. Perhaps its utility points are of greatest consideration, yet it is a pleasing rab- 


\section{SO-CALLED FANCY RABBITS}

bit to look upon, and certainly it has been wonderfully improved in the last two or three years. In size it comes between the Belgian hare and the Flemish Giant. It is not so chunky as the latter, but is less racy in appearance than the former. The head should be considerably fuller than that of the Belgian hare. This is said to be an important matter, especially with the buck, a buck with a small fine head being likely to produce undersized progeny.

The color should be uniform all over the body, head and feet. Just exactly what the standard means when it says reddish buff is not agreed upon by all breeders, one's opinion often being indicative of the kind of stock he happens to have. In any event it should not be too light a fawn, and should be as free as possible from white or black hairs. Reddish cream is called for as a belly color. Nine and ten pounds are assigned as the respective weights of mature bucks and does.

\section{The Polish Rabbit}

If all the rabbits commonly called Polish were really specimens of that breed, the num- 


\section{PRACTICAL RABBIT KEEPING}

ber in America would be very large. The fact is that most of the large white rabbits have no right to the name. The real Polish is a small rabbit, weighing not over five pounds, and its eyes are blood red when young, fading to pink with age. The coat is fine in quality, silky, short, and smooth. The ears are short and the head is fairly lean. Polish rabbits are best adapted to the cooler parts of the country because they suffer more than most breeds from the heat. Moreover their coats are injured if they are exposed to much direct sunlight. In fact, more than usual attention is required to keep these rabbits in the pink of condition, for the coat and especially the feet are certain to be stained unless the strictest cleanliness prevails. Sometimes soft bread crumbs are used to clean the coat, as they seem to remove soiled spots more effectively than anything else. Green stuff must be fed carefully, and is best withheld from young rabbits because they seem to show a tendency towards bowel trouble. Probably the Polish rabbit will never be bred as satisfactorily in America as in England, but it has many admirers. 


\section{SO-CALLED FANCY RABBITS 37.}

\section{The Angora Rabbit}

Another fancy rabbit which is bred in limited numbers is the Angora. In the eyes of many fanciers this is the handsomest of all rabbits, its long fleecy coat giving it a unique appearance. Because of this coat, though, it has no beauty of form to recommend it. Quality in the Angora lies in the perfection of its fine white fur. In parts of Europe it is said that these rabbits are often raised especially for their fur, which is used for making children's knitted caps and other garments. The coats vary from five inches to seven inches in length; sometimes in very fine specimens they run three or four inches longer.

The Angora rabbit has pink eyes, and fairly good-sized ears, which are tufted. Occasionally colored varieties are seen, blue and smoke being the most common. Because of the great difficulty attending the breeding of the colored Angoras, however, very few fanciers have taken them up. Angoras are not suitable for pets, or in fact for a fancier who is not willing to spend considerable time on them. They must be kept in roomy hutches 


\section{$3^{8}$ PRACTICAL RABBIT KEEPING}

which are perfectly clean, and have an abundance of bedding. They are not as tender, though, as some people seem to think, and will stand plenty of cold if their quarters are not damp. Fitting them for shows is a somewhat tedious undertaking unless they are kept well groomed at all times, which is the proper plan. While a well cared for Angora is a remarkably attractive bunch of snowwhite fur, a neglected specimen is an unpleasant looking object. Good Angoras weigh about nine pounds.

\section{The Silvers}

Several varieties are included among the Silvers, some of them being especially valued for their fur. The Silver Gray is supposed to be a straight product of the wild English rabbit. They have been bred there for a long time, but it is only of late years that any considerable numbers have appeared in this country. It is a robust, vigorous rabbit, and while not actually handsome, it is neat and friendly. They vary in size from four to seven pounds, smaller specimens being more 


\section{SO-CALLED FANCY RABBITS 39}

common. It is very difficult to give a comprehensive description of the color, except to say that it is a bluish black through which white hairs are scattered so as to produce the silver effect. The feet and tail should match the body color. The rabbits vary in shading according to the number of light colored hairs, so that they may be called light silvers or dark silvers. The principal point in breeding is to obtain an even distribution of the silvering all over the body. A good colored specimen resembles a gray squirrel in color.

Silver Fawns, Silver Blues and Silver Browns are shown to some extent. All of them are crosses from the original Silver Gray. The Silver Browns seem to have come from England, and the Silver Fawns from France. Argent de Champagne, sometimes called Champagne Silver, is another French member of this class, and is valued especially for its fur. It has a deep under color of blue, and a mixture of black and white hairs. $A^{\prime}$ considerable representation is now to be found in America. They make an unusual appearance, and are likely to become popular, especially if a demand for their fur develops. 


\section{PRACTICAL RABBIT KEEPING \\ The Blue Imperial}

This is an English breed, for which a woman, Miss Mabel Illingworth, stood sponsor. Although the color might be called maltese by some, it produces a decidedly bluish effect. It must be an even color all over the rabbit. The fur is rather longer than on most breeds, and is fine and soft. The eyes are deep blue. This rabbit should weigh about seven pounds, and be fairly long and lithe. Blue Imperials are not difficult to raise, and require no special attention.

\section{The Tans}

Still another class for which English breeders must have the credit is the Black and Tan. About all that can be said as to their origin, though, is that they are known. to have come from England. The number in this country is not large at present. The black Tans were the first to be introduced; the blues came from them. All the Tans are easy to raise, and should weigh from three to four and a half pounds. They are considered best for show purposes before the end of the first year. 


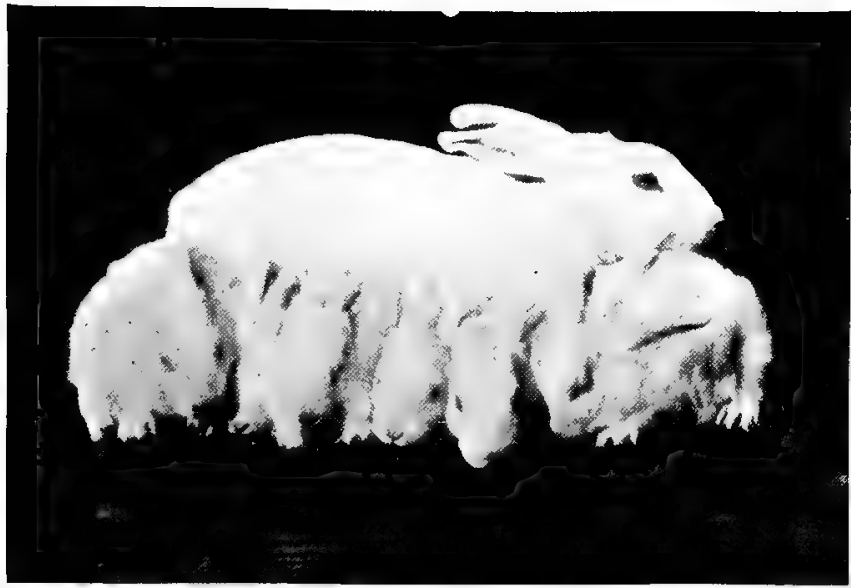

White Giant and Her Offspring

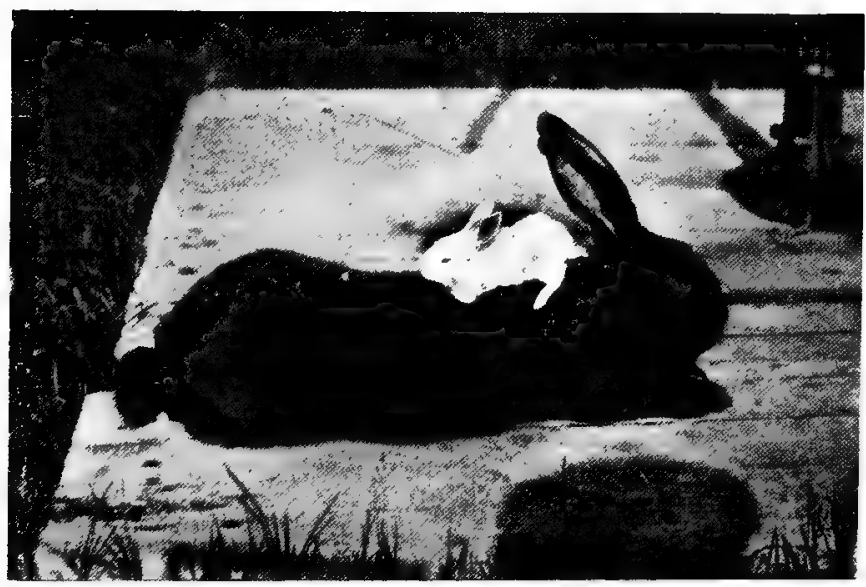

So-called Black Siberian Doe 



\section{Chapter V.}

\section{RABBITS AS PETS FOR CHILDREN.}

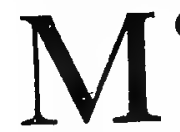

OST boys and some girls have a time in their young lives when they desire a pet rabbit above everything else. If their wish is gratified they are usually given a common white rabbit. These little pink-eyed creatures, while pretty enough, are the least desirable of all rabbits which might be chosen. They are not especially robust or prolific, and the does often make poor mothers. Of course, the true Polish rabbit, which is white and red-eyed, but considerably smaller than the rabbits usually seen, is a good kind. Polish rabbits, however, are not at all common in America. There are half a dozen breeds, though, from among which excellent pets can be chosen. They include two of the breeds most often kept for utility purposes, that is to say, the Belgian hares and the New Zealand Reds. 
Belgian hares will perhaps make the strongest appeal because of the fact that they are cheapest. They are cheap, however, not because of any inferiority, but because they are more plentiful than the other kinds. Belgian hares are among the keenest, most alert, and most interesting of all tame rabbits. They are very handsome, too, if well marked, and the boy who is interested in rabbits should be given as good specimens as possible. $\mathrm{He}$ will soon learn to know a good Belgian from a poor one, and will not be satisfied with an animal which has white feet and a gray coat. The New Zealand rabbit is larger than the Belgian, and is the largest breed adapted for children's pets. Of course boys often raise Flemish Giants, and other rabbits of that class, but on the whole the smaller breeds are to be recommended. In some parts of the country New Zealand Reds will be found even more plentiful than Belgian hares. They are especially hardy, and their sleek red coats are much admired.

For real pets, though, the Dutch rabbits cannot be surpassed. They are not very large, weighing only three or four pounds. They are 
marked in a very peculiar way, being black, blue or gray, except for a white band which extends entirely around the body just back of the head. This white band extends to the neck and down the front paws. A white patch on the nose adds to the distinctive appearance of this little rabbit. This breed is especially to be recommended because does and bucks alike are robust and lively. The does make exceedingly good mothers, and are often used to care for the neglected offspring of less faithful mothers. They are prolific, too, so that it is easy to increase one's stock rapidly, and the youngsters are readily raised. Being very tame and playful, the Dutch rabbits are perhaps the best pets which can be given to young children.

Next in value for this purpose I would name the curiously marked Himalayan rabbit, which is often seen at the shows, and invariably appeals to boys and girls alike, if they have any fondness for animal pets. They are but little larger than the Dutch rabbits, running from three to five pounds, and they have short, soft fur which is sometimes called mock-ermine. Although the body is white, 


\section{PRACTICAL RABBIT KEEPING}

the ears, nose, feet and tail are so brown as to be almost black. The eyes are pink, and very bright. It is an interesting fact, and one that may puzzle youthful owners of Himalayans, that when born they have no dark markings at all, being white all over. By the time the youngsters are three or four weeks old, small colored spots will appear on the nose and in a few weeks more the real Himalayan characteristics will be in evidence. Because of its playfulness, its unusual appearance and its vigor, the Himalayan rabbit is a most desirable pet.

Rabbits that are kept for pets do not need elaborate hutches, and many a boy has fashioned a satisfactory home for his pets from a drygoods box. One important point, though, must be remembered. The hutch must be kept dry and clean. Otherwise it is impossible to be successful in maintaining the health of the animals. Over-feeding is another point to be avoided. Children always like to see their rabbits eat, and are tempted to give them more food than they ought to have. This applies especially to young rabbits which soon become pot-bellied if overfed, and particu- 
larly if given green food. Other troubles are likely to follow, and the venture in rabbit keeping prove disastrous.

It often happens that children are enthusiastic when they begin keeping rabbits, but after a few weeks find the work of keeping them fed, watered and otherwise cared for becoming monotonous. Wise parents will not allow their children to own any animal longer than they are willing to give it the attention which it needs. 


\section{Chapter VI.}

\section{HOW TO BEGIN RABBIT KEEPING}

D ROBABLY it goes without saying that the only proper way to begin rabbit keeping is in a small way. To start in with a large number of animals before one has learned to care for them properly is to invite prompt disaster. It is true that there is nothing very complicated or difficult about rabbit keeping, but what there is to learn should be learned thoroughly before one gets too deeply into the business. It is important, too, that the beginner investigate the various breeds before he makes a start. Otherwise he may find a little later that he prefers a different breed from the one which he has chosen. Then it will be necessary to begin all over again. In making a selection one must consider the market to be supplied or the purpose for which the animals are to be raised. It makes a difference whether one 46 


\section{HOW TO BEGIN}

wants rabbits for pets, rabbits for meat, rabbits for fur, or rabbits for exhibition. Something depends, too, upon the part of the country in which one lives.

Perhaps it is better for the average beginner to start with one of the medium sized breeds, like the Belgian hare or the New Zealand Red, rather than with the Giants. These are good utility rabbits, and yet show stock can readily be built up if one starts with well bred animals. In the east the Belgian hare is more likely to be chosen, while on the Pacific coast New Zealand Reds have the preference. It is better to obtain some skill by handling these rabbits for a year or two before starting in with purely exhibition breeds. Certainly no one should start rabbit keeping by buying either English or French lop-ears.

The number of rabbits to start with will depend somewhat upon the size of one's purse and the amount of room available. Perhaps the simplest plan is to start with a doe which has been bred to a young buck. By all means buy a young animal, even though you have to pay a little more. It isn't necessary to keep a buck at any time, for you can always have your 
does bred to a good buck owned by a more extensive breeder for a small fee. It is much better in the long run to adopt this practice, providing you can secure the service of a high grade buck, rather than to use a poor buck in your own hutches. It hardly pays to purchase an expensive buck simply for breeding purposes, if you have only a few does. By the time you have increased your stock to six or eight breeding does, you will be justified in buying the best buck that you can afford. Of course this is speaking only in a general way. You may be so situated that it will be necessary for you to have a buck at the beginning, although there is usually no difficulty about purchasing a bred doe.

The amount to pay is a question which cannot be readily decided for you. The following are the prices quoted in the circular of one of the largest and best known breeders in the eastern states:

Belgian Hares, young stock, eight to sixteen weeks old, bred from prize-winning bucks and good does; price per pair, \$3.50; per trio, $\$ 5.25$. Young stock of the highest quality, bred from registered bucks and does; many 


\section{HOW TO BEGIN}

of them are fit for show purposes; prices per pair, \$5.50; per trio, $\$ 8.00$.

Heavyweight Belgians which combine size with good color, young stock, eight to fourteen weeks old, price per pair, $\$ 4.00$; per trio, $\$ 6.00$.

White Flemish Giants, good size and true Flemish type; price per pair $\$ 5.00$; per trio, $\$ 7.50$.

Black Giants, young, eight to sixteen weeks old; price per pair, \$5.00; per trio, $\$ 7.50$.

Light Gray Flemish, first-class young, eight to sixteen weeks old, at $\$ 4.00$ per pair; $\$ 6.00$ per trio. Highest quality stock from winners, $\$ 6.00$ per pair.

New Zealand Reds, young stock, eight to sixteen weeks old; price per pair, \$5.00; per trio, \$7.50.

Giant Crosses are ideal for table purposes, and sell readily anywhere. They are crosses between Black Giants and White Giants, New Zealand Reds and White Giants, Heavyweight Belgians and White Giants. Young, eight to sixteen weeks old. Price per pair, $\$ 3.00$; per trio, \$4.50.

Giant Crossed Does, heavy in young; these 


\section{PRACTICAL RABBIT KEEPING}

does were bred from heavyweight bucks and good utility does. They are now mated to large, pure-bred bucks, and will soon produce their litters. Price each, $\$ 3.75$ to $\$ 6.50$.

Blue Imperials, exceptional color and good pelts. Price for young stock, eight to sixteen weeks old, fit for any show room, \$17.50 per pair. Extra does, \$10.00 each.

Himalayans, young, bred from winners; price per pair, \$7.50; per trio, \$II.OO.

Good English, bred from winners; price per pair, \$8.00.

Angoras, young, in black, white, orange, blue, and broken colors at $\$ 3.00$ to $\$ 10.00$ per pair.

These are the lowest prices at which good stock is offered. In many cases the beginner should expect to pay rather more.

There is one thing to avoid above all else. You will find many alluring advertisements even in reputable magazines and papers, leading you to believe that you can make a fortune in a few weeks by buying rabbits from the firms inserting the advertisements, and selling back to them the stock which you raise. In the rabbit industry, as in all lines of business, 


\section{HOW TO BEGIN}

there are fakers and frauds aplenty. This does not mean that every concern advertising to buy back stock is conducting a campaign of misrepresentation, or is not honest. You may be sure, though, that any concern making exaggerated claims is not above suspicion.

If you can see your stock before you buy it, that will be a great advantage. Perhaps, however, you are not familiar enough with the breeds to know a good from a bad specimen. In that event it certainly will pay you to get an experienced rabbit breeder to go with you, even if you have to reimburse him for his time. At any rate, buy from a breeder who is a member of the National Breeders' and Fanciers' Association, for then you have a chance of obtaining redress if the stock is misrepresented. In every section of the country there is a representative of this association to whom you can appeal if you think you have been wronged. (See appendix.) There are plenty of good, reliable dealers from whom you can be safe in buying. Many of them have their best stock registered. Buy registered stock when purchasing high priced specimens. 


\section{PRACTICAL RABBIT KEEPING}

If you order your rabbits by mail, examine them at the express office before signing for them. First of all, look at the inside of the feet to see if the hair appears wet and rough. If you find such a condition, ship the rabbits back at once. The trouble may be only a slight cold, but on the other hand, it may be incipient snuffles, which no one wants to get into his rabbitry. No end of beginners have been disgusted after a few weeks because they have started with stock in this condition.

It is well to examine the interior of the ears. Unless they are clean inside, you may expect canker. If you find the rabbit shaking its head frequently, and pawing at its ears, you may safely infer that something is wrong. It is barely possible that the rabbits may have lice, although they are not often found. It will be well to turn back the fur to look for vermin, in any event. They sometimes occur when rabbits are kept in filthy quarters or adjacent to a hen house. It is also advisable to examine the reproductive organs for signs of disease there.

A good healthy rabbit has a lively, alert appearance, with a bright eye, the white of 
which has no tinge of yellow. The body should not be pot-bellied, but lean and firm. Of course rabbits that are very thin are likely to be in poor condition. If the dung is firm and in round balls you can assume that the digestion is good.

You may need the assistance of an experienced breeder to determine the good or bad points of a rabbit which you are buying, and such a precaution should be taken if you are paying more than a nominal price. You yourself, however, can judge of the rabbit's condition if you bear in mind the points just discussed.

One very important matter is to be sure of the sex. Parhaps no more trouble has been experienced in buying rabbits than by having the animal you bought for a buck turn out to be a doe, or vice versa. This is a matter where many breeders who are selling stock err. Some of them, without doubt, sell a buck for a doe, trusting that the buyer will not discover the mistake until so much time has elapsed that he will not feel like making a complaint. It is a simple matter to determine the sex of an animal after it is a few weeks old. Turn 


\section{PRACTICAL RABBIT KEEPING}

the rabbit on its back on your knees and press gently on the parts with the thumb and forefinger. After one or two trials you will be able to determine at a glance between the doe and the buck. When rabbits are mature, experienced breeders can often tell them apart by their general appearance, but the novice will have difficulty in doing so, and even old breeders must resort to a physical examination to tell the sex of young stock.

With this simple exposition of the important matters to be borne in mind when buying stock, the prospective rabbit keeper will be able to make at least an intelligent start. 


\section{Chapter VII.}

\section{HOUSES, HUTCHES AND YARDS}

T $T$ is quite possible to keep rabbits in yards out of doors, and when the Belgian hare boom was at its height some years ago, many of the leading breeders constructed houses with yards attached, very similar to poultry houses. As a rule, though, rabbit keepers now-a-days confine their animals to hutches. Of course it is a simple matter to make a hutch from a dry-goods box or to make a series of hutches by the use of second hand lumber or perhaps boxes from the grocery store. The hutches may be very inexpensive and yet perfectly satisfactory. In England. where many wealthy men and women are included among the rabbit fanciers, some elaborate houses are to be found. In some houses mahogany doors and ornamental latches or door fasteners are common enough. Perhaps it goes without saying, however, that the animals to be found in these pretentious 


\section{PRACTICAL RABBIT KEEPING}

rabbitries are seldom superior to those kept in much more modest quarters and owned by breeders having more skill than money.

The most important point in connection with any hutch or house is that it should be absolutely dry and free from drafts. It should be reasonably roomy, too, because rabbits suffer if confined to very narrow limits. Of course much depends upon the breed. It is not necessary to have as large hutches for rabbits like the Himalayans and the Polish as for Belgian hares and New Zealand Reds, while Flemish Giants need larger hutches than any of the breeds mentioned. It is sometimes thought by fanciers that there is an advantage in having small hutches when smaller rabbits are being raised for exhibition purposes on the assumption that the rabbits will not grow large because they have so little room to move around in. The fact is, though, that exercise is of quite as much importance, because without it the animals are likely to get fat and logy instead of measuring up to their true type. The mistake is of ten made of having hutches too low, especially when fancy rabbits are being bred. The result is that the animals 


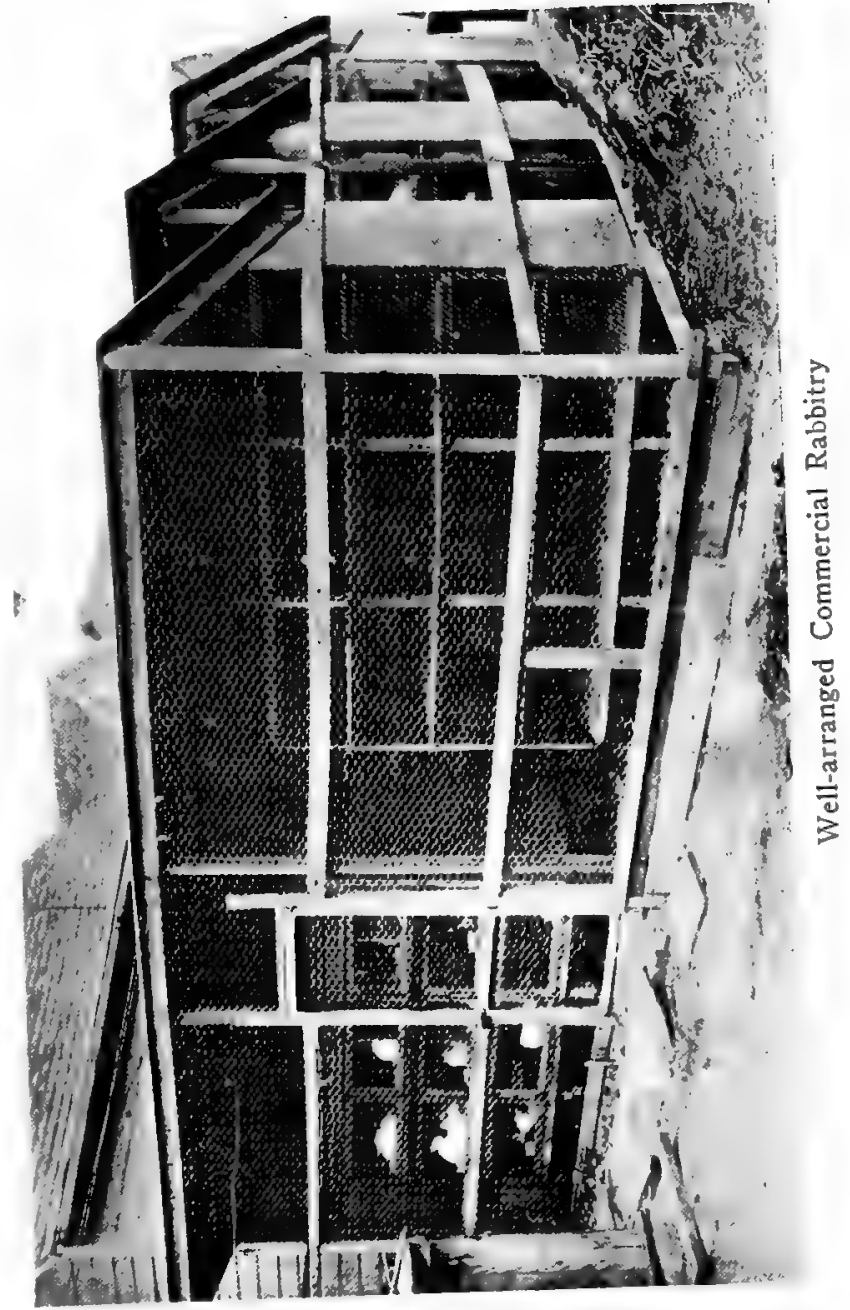





\section{HOUSES, HUTCHES AND YARDS 57}

acquire a hunched-up appearance instead of the graceful, free habit of movement which comes from being able to stand erect or climb up the wire front of the pen.

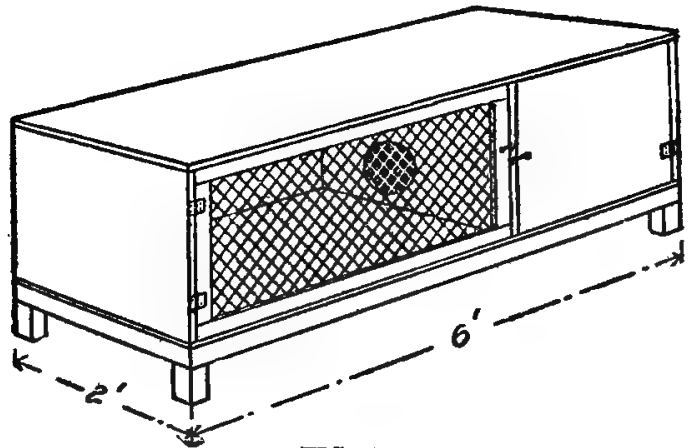

FIG. 1.

After careful study of many types of hutches in use in America and across the water, David E. Lantz, of the United States Department of Agriculture, has presented the accompanying designs for the consideration of practical rabbit keepers. For ordinary purposes the hutches which he recommends can hardly be improved upon. In his bulletin describing the hutches Mr. Lantz deals chiefly with Belgian hares, but the hutches are adaptable to any breed, except that their size may be varied as desired. Mr. Lantz describes his hutches in the following words: 
"A convenient indoor hutch (fig. I) is one 6 by 2 by 2 feet, with a movable partition dividing off a third of the space at one end for a nest and sleeping chamber. The partition has a smooth hole to permit passage of the animals from one part to the other. The front of the hutch has two doors, one of wire netting, the other of wood. The wooden door opens to the sleeping chamber and should

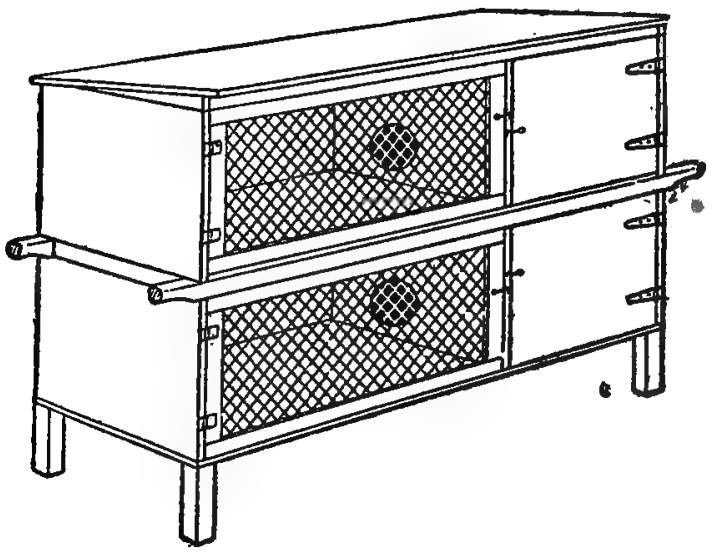

FIG. 2.

close tightly. It is best to use metal hinges for the doors. The partition may slide in a groove between the doors or may be put in and taken out through one of the door openings. 


\section{HOUSES, HUTCHES AND YARDS 59}

"Outdoor hutches should have sloping roofs and overhanging eaves to protect them from rain. The screened door should have a sliding cover of wood or be fitted with a removable cloth cover. Small holes bored near the top of the hutch will afford all necessary ventilation.

"Movable hutches (fig. 2) have some advantages. They may be carried outdoors in fine weather and taken back under shelter at night or during storms. Long, narrow cleats projecting at both ends of the hutch are all that are needed to convert the ordinary hutch into a movable one. Two forms of outdoor hutch sometimes used are shown in figures 3 and 4. That in figure 3 has no floor except a

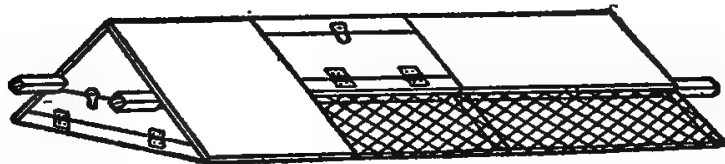

FIG. 3.

wire screen, permitting the rabbits to eat grass or other herbage that projects through the netting."

When the rabbits are to be in small quarters, it is a customary plan to stack the hutches, 
making three tiers. This plan saves labor as well as space, yet it has its disadvantages. The fundamental essential in the rearing of rabbits is cleanliness, and it is more difficult to attain complete sanitation when the hutches are stacked than when each hutch stands by itself. A method which has been adopted by some
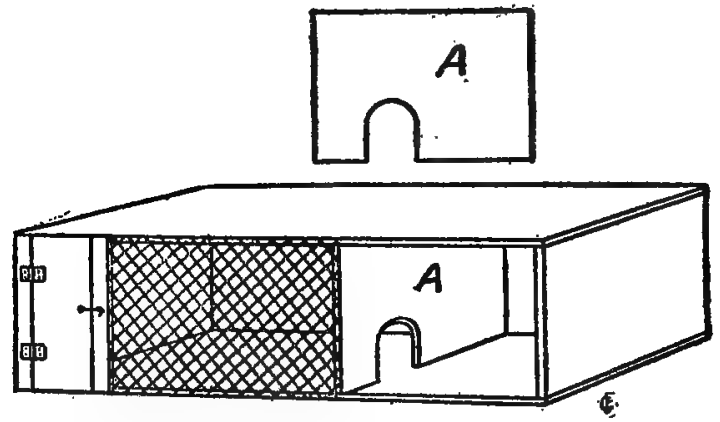

FIG. 4.

successful breeders is to have each hutch constructed with a sloping roof, a block being so placed as to elevate the floors of the upper hutches to the proper height. Then the liquids coming through the floors of the hutches are drained away instead of soaking through into the hutch beneath. It is desirable to have the roof of each hutch covered with heavy roofing paper, or better still, with tin.

So-called self-cleaning hutches are often 


\section{HOUSES, HUTCHES AND YARDS $6 \mathrm{I}^{-}$}

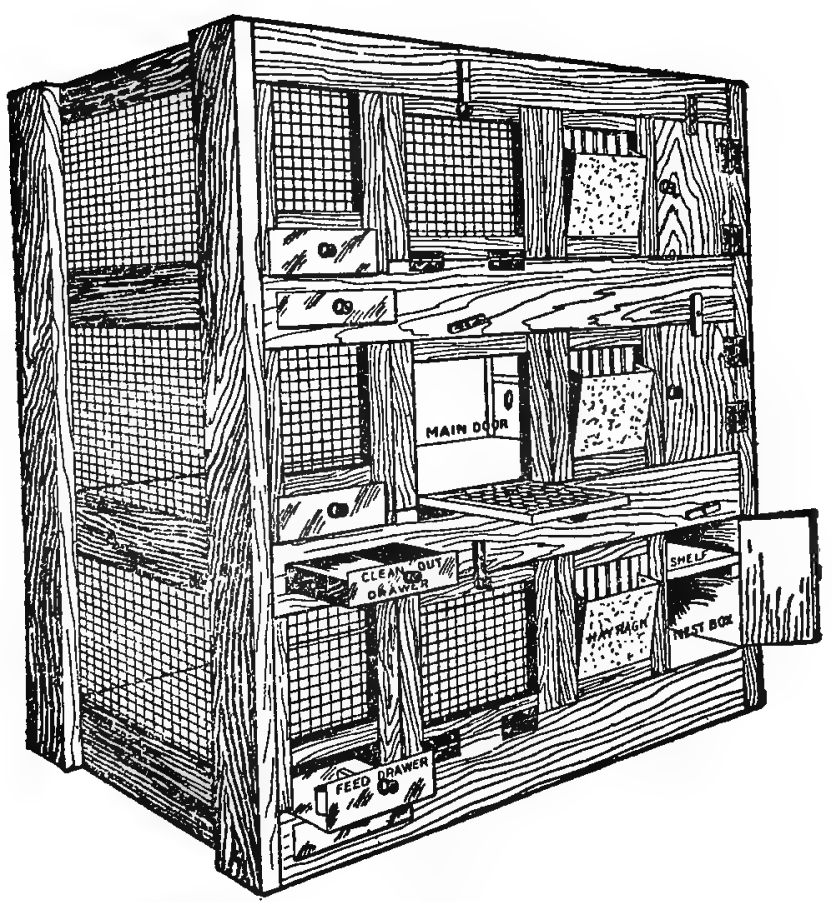

FIG. 5. 
recommended, and are used to a considerable extent, especially on the Pacific coast, and in other warm sections where large out-door rabbitries are common. These hutches have floors made of narrow boards spaced about an inch apart, or floors of closely woven wire netting or hardward "cloth. A good heavy cloth is needed as a matter of course, and must be well supported so that it will not sag. Sometimes a few loose boards are laid on it. Very little bedding is used in such a hutch, and the droppings fall through, being gathered up from the ground or from a box underneath. In some rather elaborate hutches (see fig. 5) including one or two patented designs, drawers are arranged under the wire floor to receive the droppings. Of course this plan makes cleaning very easy. Even with such an arrangement, though, it is advisable to have a scraper and a brush for getting into corners.

The average rabbit keeper, especially the amateur, is satisfied with a tight floor covered with sawdust or some other absorbent. It is best, of course, to have the floor made of matched boards, and with as few cracks as possible. Many times a box about eighteen inches 


\section{HOUSES, HUTCHES AND YARDS 63}

square and three inches high, filled with sawdust and placed in a corner of the hutch, will serve a very useful purpose, and one which the rabbits soon recognize. Then the droppings are mostly found in this box, and cleaning is greatly facilitated. Some rabbit keepers simply smear a corner of the hutch with a little of the dung, with the result that that corner is usually resorted to by the rabbits with the same result as when a box is used.

The other fittings of the hutch, however it is constructed, must include a nest box, unless the apartment is to be given over wholly to the use of the bucks or young animals. In the hutch described by the Government agent, the nest box is arranged for in the general design. Oftentimes, though, it consists simply of a smaller box placed in a corner of the hutch. This box should be about eighteen inches square and about a foot high. Of course the size will depend somewhat upon the breed of rabbits which are to use it. The box should have no top, but should be inverted on the floor of the hutch. At one end an opening large enough to admit the doe should be made, but this opening should be placed if possible 


\section{PRACTICAL RABBIT KEEPING}

away from strong light. Oftentimes a few holes are bored in the side of the box near the top to allow for additional ventilation when the weather is very warm. A nest box of this kind is easily removed for cleaning and costs practically nothing. Some commercial rabbit breeders prefer to have a permanent nest box in one corner with a secondary door in the outside wall of the hutch so that the nest can be examined from without. This plan makes it an easy matter to remove surplus youngsters or rabbits that were born dead, the work being done without the knowledge of the doe if the time is chosen when she is feeding outside the nest box. It is well to have the entrance opening three inches from the floor, so that the new born rabbits will not roll out. The doe will jump on the box to escape from her offspring.

There are several ways of arranging for the easy cleaning of an improvised hutch. One plan is to have double wire doors. Another and less expensive method calls for a wire covered frame which fits tightly against the front of the box and contains a small door. When the hutch is to be cleaned the entire front can be taken off. Another way is to have a board 


\section{HOUSES, HUTCHES AND YĀRDS 65}

about six inches high placed across the front of the hutch and resting on the floor, held in place with a button or a hook at each end. The rest of the space may be covered with wire. At cleaning time this board may be removed and a scraper used to pull out the litter. This plan economizes work when a wheelbarrow or cart or perhaps a litter carrier on a track is used to remove the rubbish and offal.

If a rabbit raiser is to keep his animals in the open air all the year round, he will need some kind of roof or shelter which will project a foot or more over the front of the hutch or stack of hutches to exclude both rain and a certain amount of direct sunshine. There is no better disinfectant than sunlight, and most rabbits like to bask in it. At the same time, it is exceedingly injurious in mid-summer when the weather is very hot. Moreover, exposure to direct sunlight for any length of time fades the coats of several breeds, like the Himalayans, the Imperials and the Tans. Many breeders contend that the coats of Belgian hares are damaged by sunlight, but this claim is often carried much too far. No doubt 
an excess of direct sunshine impairs the lustre of the coat, and perhaps causes it to appear somewhat rusty. This result will not follow, though, unless the rabbits are kept in the bright sunlight for many hours at a time. It is not wise to keep Belgian hares in semi-darkness, as some breeders have been taught to do. Even though their coats may be benefited slightly from this treatment, which is a doubtful matter, their health is pretty certain to suffer out of all proportion to the advantage gained.

It may be advisable in northern parts of the country and in Canada to have some kind of shed or other building for housing the rabbits in mid-winter. At the same time, this is not necessary, and it is better, as a matter of fact, to have the animals in outside hutches than to keep them in any building which is damp and gloomy. When outside quarters are to be adopted, the rabbit keeper must provide an extra amount of straw or hay for the rabbits to burrow in. It will be for the comfort of the little animals, too, to construct a board shutter to be placed at the front of the hutch at night, a small opening at the top providing ventila- 


\section{HOUSES, HUTCHES AND YARDS 67}

tion. In lieu of such a shutter, canvas, oiled muslin, or even heavy burlap may be used, ventilating openings being bored at the ends of each hutch. Some breeders use no front covers, even in very cold months.

Now that rabbit breeding has come to be a recognized commercial industry, more attention is being given to the construction of rabbit houses. Several leading breeders have long buildings with a series of alleys running. through them, and with two tiers of hutches. opening upon each alley. These buildings are arranged in such a way as to economize time and labor, and it becomes possible for one man to care for five or six hundred rabbits. On the Pacific coast, some of the rabbitries: have open sides all around, but are covered with a broad roof to exclude the rain and hot sun. The hutches, usually of the self-cleaning type, are arranged in long rows under this roof, usually back to back so as to face on parallel alleys. Rabbit keeping in the warmer parts of the country has some advantages, yet the long rainy season is quite as hard for the animals to endure as the kind of winter weather to be found in the east and north. 


\section{PRACTICAL RABBIT KEEPING}

Amateurs with only a few rabbits can often give them more room than the commercial grower. It is an excellent plan to have an outside run in connection with a hutch. This may be made of wire netting mounted on legs, or it may rest on the ground. Even in the latter case it should have a floor either of boards or wire. Too much emphasis cannot be placed upon the necessity of having such a run or in fact any kind of outside hutch made very strong. Otherwise the rabbit keeper is likely to have his stock wiped out by the depredations of dogs. Dogs sometimes get wildly excited at the sight of a rabbit, even in a pen, and will go through an ordinary wire front. Even when it is impossible for a dog to reach the inmates of the hutch, the latter may be badly injured by fright. A doe with young in the nest may pull them out, and destroy them in her terror. Or in the case of a bred doe, a premature birth may be brought about. Dogs often become a serious menace to the rabbit keeper, and must be taken into account when a rabbitry is being planned. It is advisable to cover hutches with wire of a close enough mesh to exclude rats and mice, 


\section{HOUSES, HUTCHES AND YARDS 69}

which are likely to gather wherever grain is to be found.

In some parts of Europe what is called the Morant system is followed. Many French rabbit keepers think this is the ideal way for raising their animals during the warmer months. The hutches are light enough so that they can easily be moved, and they have raised nests so that the rabbits can feed beneath them. These hutches have no floors, but are placed on the grass and moved from day to day. The simplest way is to have projecting handles, although French fanciers simply use broad hooks to which bars are attached when the hutches are to be moved.

Of course hutches of this kind must be very strong or they will soon fall to pieces under the constant lifting about which must be given them, as well as their exposure to the weather. They must be made firmly enough, too, so that they can resist the inroads of dogs, cats, and in rural districts, of foxes and other wild animals. Moreover, a considerable amount of grass land is necessary because the same area. should not be fed over more than twice each season. Otherwise there is danger of getting: 


\section{PRACTICAL RABBIT KEEPING}

the animals infected with internal parasites, known as Coccidiosis, which are induced by unsanitary conditions, and especially by keeping rabbits on fouled ground.

While the Morant system, therefore, would seem at first thought to be an ideal one, because of the saving in food affected, as well as by the saving in time and labor, it is not satisfactory enough, all things considered, to cause its general adoption. The hutch described by Mr. Lantz, and illustrated in figure 3 , is designed for grass feeding, and is a good type for American conditions. Even though the Morant system, which gets its name, by the way, from its French originator, may not be adapted for general use, it may be employed to some extent, a few hutches being used for individual animals or for young stock above the age of three months.

The question is often asked why rabbits cannot be kept in large enclosures having tight wire fences. This plan was tried out more or less extensively at the time of the Belgian hare boom already mentioned. It was thought then that by fencing in several acres, the rabbits could be turned loose and allowed to multiply 


\section{HOUSES, HUTCHES AND YARDS $7 \mathrm{r}$}

without let or hindrance, the expectation being that in a few years a very large number would have been accumulated at almost no expense for feeding or care. This alluring proposition invariably failed to work out according to specifications. Belgian hares and all the other domesticated rabbitș, being made breeds, are not adapted to even a semi-wild life. If turned out into the woods or fields to shift for themselves entirely, they are soon entirely exterminated. Like cows or sheep or any other of the farmer's livestock, they need man's protection and care.

It is possible, though, to keep animals in a small yard or court if the number is not too large. A paved court, or one with a board floor, can be handled in much the same way as a hutch, except on a largér scale, and will accommodate a considerable number of young animals. Wire netting may also be used to cover the bottom of an enclosed yard. It is an advantage to have it an inch or two under the surface. The rabbits will try to dig through this, but after one or two attempts will give up. Unless prevented by some kind of a barrier, the rabbits will dig holes all 


\section{$7^{2}$ \\ PRACTICAL RABBIT KEEPING}

through the ground, and some of these holes will very likely lead to a point outside the fence and upward to liberty. Unless such a yard is connected with an inside hutch, there should be boxes into which the animals can retreat when alarmed.

A rabbit fence must be firmly made of heavy poultry netting five or six feet wide. One-inch mesh is best. If such yards can be used for one season and then shifted, this plan may be followed successfully in rearing rabbits out of doors. There is always danger, though, that the ground will become foul and the difficulty already mentioned creep in, with very serious results. Moreover, much more space must be used for a limited number of rabbits than when the hutch system is adopted. For that reason, therefore, most rabbit keepers now confine all their stock to hutches, except for adjoining runways.

Some of them have special hutches for young stock, making them long and rather narrow. This is rather a good plan, for it gives the youngsters a chance to exercise freely. It must not be supposed from this, though, that a large number of young rabbits 


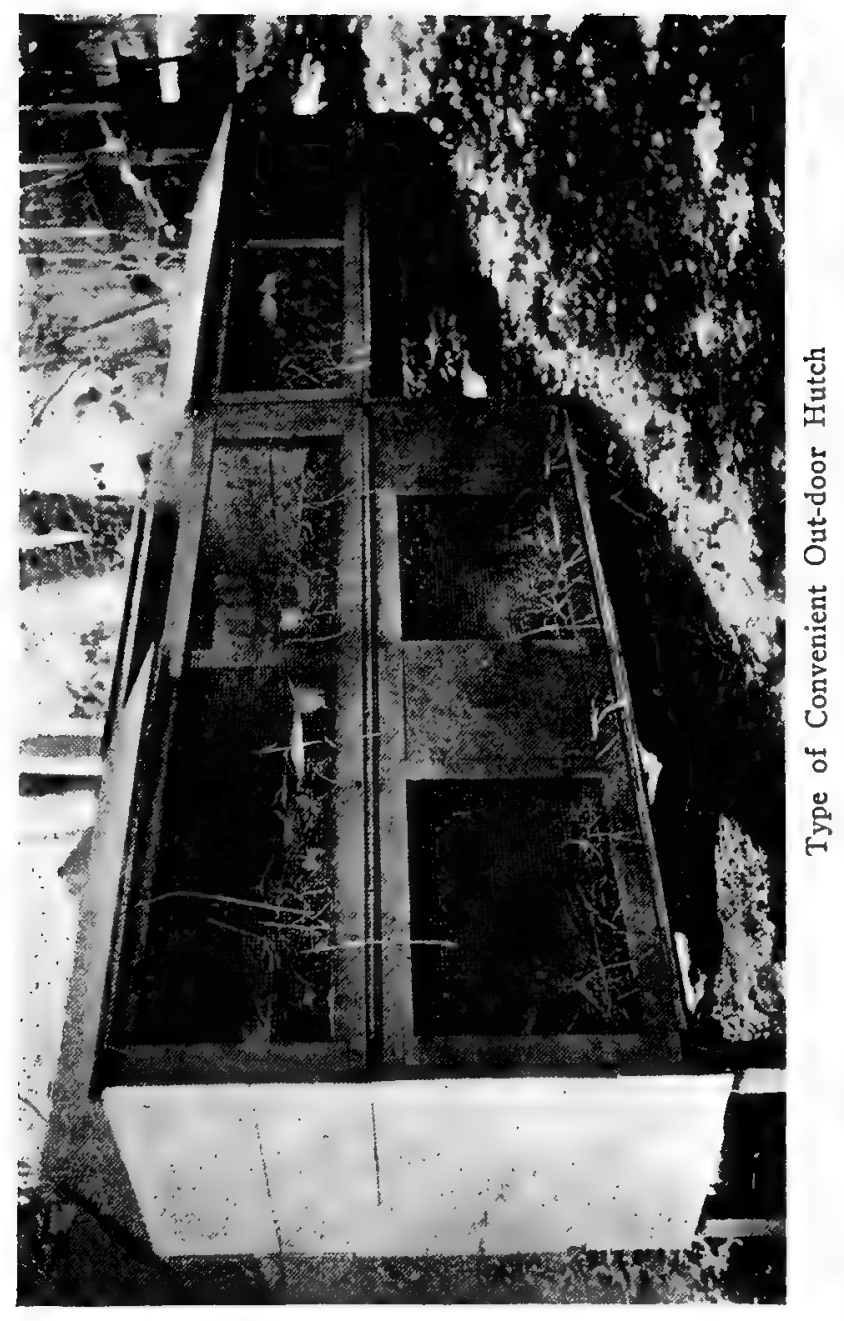





\section{HOUSES, HUTCHES AND YARDS 73}

can safely be put together. It is best not to house more than six or eight in one hutch, especially if high bred stock is being kept. It doesn't matter so much with young animals that are simply being raised to the meat age, because they are to be slaughtered, although, as with chickens, there is likely to be one animal which will be stronger and bolder than the others and get more than his share of the food. 


\section{Chapter VIII.}

\section{THE GENERAL CARE OF RABBITS}

$T$ is of the greatest importance to keep the
rabbits free from dampness and drafts. Every poultry keeper knows that he is certain to have trouble with his hens if he houses them in damp, drafty quarters. It is the same with rabbits, whatever the breed may be. Like poultry, most breeds can endure a low temperature, providing the air is dry and enters the house only at the front or through special ventilating devices. It is much better to have the animals in an open hutch out of doors, with a plentiful supply of hay or straw to burrow in than in a shed or other building where the sun-does not enter, and a feeling of dampness prevails. At the same time, a certain amount of shelter is desirable. Various arrangements of hutches to make this possible, where there is no special rabbit house, will be described in a succeeding chapter.

\section{4}


The hutch must be kept perfectly clean, for sanitation is the price of success in rearing rabbits. Different devices to make cleaning easy are on the market and can be purchased at a low price. It is not difficult to make a short-handled hoe, or scraper, at home, and a long-handled stove shovel will be found useful, especially for getting into the corners and for handling sawdust. It is a good plan to have a fibre or tin pail to carry away the droppings and litter, or to use a box mounted on wheels. The latter plan is a good one when one has a considerable number of hutches to be cared for. A box on a small wheelbarrow can also be used to advantage. Some sort of deodorizer or disinfectant should be kept on hand for use in the house and in the hutches. Every hutch should be carefully cleaned and disinfected before a new rabbit is put into it.

Breeders differ as to the kind of absorbent to be used, or whether to use any at all. With self-cleaning hutches they are not needed. Dried peat, if it can be obtained, is especially good. A preparation of this kind for use in poultry houses is on the market, and will be found equally useful by the rabbit keeper. 


\section{PRACTICAL RABBIT KEEPING}

Sawdust is used by many breeders, and is a good material, providing it is not from oak trees. Oak sawdust like oak shavings is not desirable.

While sunlight is desirable for sanitary reasons, all rabbits suffer intensely from the heat, and their hutches should be so arranged that they will be sheltered in the middle of the day. Sometimes this is accomplished by having projecting eaves at the front. Such an arrangement also prevents the rain beating in when the hutches are out of doors.

While out-door rabbit keeping has much in its favor, one must always guard against the inroads of dogs. With rabbits as with sheep, there seems to be something which arouses the lust for killing in many canines, regardless of breed. All over the country there are rabbit keepers who can testify to serious losses from dogs which have broken into the rabbitry and gone right through wire doors in order to attack the terrified and helpless inmates. The writer knows what it is to have valuable animals destroyed in this way, and feels it necessary to give this warning.

There seems to be a common belief among 
boys that the right way to lift a rabbit is to grab it by the ears. This is wholly wrong, as every rabbit keeper of experience knows. Many times lop ears are produced as a result of such rough handling, and a lop ear spoils an otherwise good specimen. Moreover, handling by the ears causes the rabbit pain, and is a most cruel practice. There is one right way to lift and carry a rabbit, and one which all youthful rabbit keepers should be taught at the beginning. Just behind the shoulders there is a bunch of loose skin which can be readily grasped by the hand, in much the same way as an old cat takes her kitten in her mouth by the scruff of the neck. It does not injure or hurt a young rabbit to lift it in this way. Quite of ten a rabbit breeder following this practice will also close his fingers around the ears so that a superficial observer might think that the weight of the rabbit was carried by the ears. When a rabbit is heavy it is best to use two hands, one holding the animal in the way mentioned, while the other is placed under the hind quarters and allowed to carry most of the weight. As a rule rabbits dislike to be handled. Sometimes they will struggle 


\section{PRACTICAL RABBIT KEEPING}

fiercely, but can be controlled if held by two hands as described. It is always advisable to watch out for the hind feet, for the toenails are likely to be sharp, and rabbits have surprising strength in their hind legs, as everyone realizes who has heard them stamp on a board floor when startled or excited. The resounding thump which they give the boards can be heard a long way.

Rabbits are capable of fighting viciously and of doing each other much injury. It is unsafe to keep bucks together, unless they have been castrated, after they are three or four months old. Sometimes a number of bucks which have been brought up together have got along peaceably, but usually there is much fighting. Two old bucks must never be allowed to get together under any circumstances. Sometimes they will disfigure one another by fighting through the wires of pens which are close together. It may even happen that a doe which has been placed with one buck will be maltreated if put with another buck because of the odor which she carries.

It is very important to avoid handling young rabbits before they leave their nests, and 


\section{GENERAL CARE OF RABBITS 79}

even for some weeks afterwards. It is a good plan to rub your hands over the fur of the mother before handling very young rabbits.

It is wise to watch out for mice, which often get into a rabbitry looking for grain. Not only do they cause a loss by eating this grain, but they are likely to disturb the does so that they will neglect their young. 


\section{Chapter IX.}

\section{WHAT AND HOW TO FEED}

66 TT HAT shall we feed our rabbits?" That is one of the first questions asked by the beginner, but even the most experienced rabbit keepers disagree as to the answer. Some rabbit keepers will tell you that dandelions and plantains are exceedingly injurious, but that cabbage is an ideal green food. Others will decree that plantains and dandelions constitute an excellent green ration for rabbits, but that cabbages should be fed most sparingly. One writer asserts positively that green food which is wet is to be shunned with the greatest care. Another states that no harm at all is done in feeding green food wet. These are only a few of the various contradictory statements which will puzzle the novice when he comes to investigate the matter of providing suitable rations for his stock. 
WHAT AND HOW TO FEED 8r

After all, though, common sense must govern the feeding of rabbits, as of all stock. Something depends upon the feeding habits which the rabbits in any section of the country have developed. Young animals that have been kept closely confined all winter and given very little green food are likely to suffer if allowed an unlimited quantity of wet grass or other green stuff in the spring. If they are gradually introduced to garden produce, it will soon have no injurious effect whether fed wet or dry. Rabbits that have their liberty in yards, likewise wild rabbits and hares feed on wet grass or vegetables with impunity.

The trouble ascribed to feeding wet grains most commonly is actually caused by allowing the grains to become moldy. Even grass that is gathered when wet will heat if allowed to stand only a few hours and become unfit for food. Cabbage leaves, dandelions, celery tops and any other food stuff of this kind thrown into a corner of the rabbitry and left unconsumed will soon reach a condition which makes it injurious for feeding. With this fact in mind, the amateur will know about how to utilize the green stuff from his garden or 
lawn, which properly husbanded will reduce the cost of feeding his animals during the summer months to a very small amount. If more grass or clover is gathered than can be eaten up at once, it should be spread on a wire rack so that it will cure without molding or sweating. Then it can be used with perfect safety: It is best to feed a variety when using green stuff rather than to depend wholly upon any one article like dandelions, for example, cabbages, or beet tops.

Some rabbit keepers lay great stress upon the value of cabbages, especially in the winter, although others, as has been stated, condemn its use at any time. Certain it is that cabbages often constitute the only green food that many rabbits get during the winter months, because cabbages can be kept for a long time if properly stored. It may be said in this connection, though, that the cabbages should not be allowed to freeze if they are to be fed to rabbits. They should be kept in a cool place so that they will not decay, but in a place that is above the freezing point. If any of the outside leaves are beginning to decay, they should be carefully removed. There is one disadvan- 
tage in the feeding of cabbages, and one which should be considered when the rabbits are kept indoors. This vegetable causes the urine to have a very strong odor, which in many cases is very objectionable. Some such result follows the use of certain other vegetables, but it is particularly pronounced in the case of cabbages.

It is of decided advantage to have a garden, because the liberal use of vegetables and green foods helps to reduce the cost of raising one's rabbits, and because the animals thrive especially well on such food, although it will need to be supplemented with some grain and hay. In this country great stress is laid upon the value of carrots, which are called the best vegetables for. rabbits of all kinds. It is claimed that carrots help to create a liberal flow of milk if fed to a breeding doe, and that they aid in producing a fine, glossy coat when given to exhibition animals. Yet it is quite possible that the value of carrots is somewhat overemphasized, possibly because of the fact that rabbits are exceedingly fond of carrots and eat them with the greatest avidity.

English breeders who have had more ex- 


\section{PRACTICAL RABBIT KEEPING}

perience than most of the members of the fancy in this country pin their faith to parsnips, although amateurs in England and in France favor the theory of the superlative value of carrots. Analysis shows that parsnips have greater food value, and the same richness in sugar and essential oils. At the same time it must be admitted that any food which provokes the appetite is likely to be more beneficial in some ways at least than that which is eaten with less relish. Parsnips should be grown, at any rate, and can be left in the ground all winter, being ready for use in the spring as soon as they can be dug. The amount kept outside should be limited, though, because parsnips have to be used quickly after they are dug in the spring. Of course a few boxes of parsnips may be stored in the cellar in the fall. Both carrots and beets should also be grown for winter use. Turnips may be added to the list, especially the Swedes called rutabagas, as they can be grown cheaply and assume large size in good ground. It should be stated in passing that beets which have been allowed to freeze should never be fed to rabbits. 


\section{WHAT AND HOW TO FEED 85}

The statement is sometimes heard that vegetables stored for winter in the average cellar will wilt in a few months, and wilted vegetables, as all admit, are not desirable for stock any more than for humans. With a little care, though, this wilt can be prevented, and the vegetables kept fresh and crisp until spring. It is only necessary to store the vegetables in clean sand. A layer of sand should be put in the bottom of the box, and the sand sifted around and over each layer of vegetables. If sand is not available, autumn leaves can be used as a substitute. They may not be quite so efficient, but they will keep the vegetables in good condition for a long time. If the cellar happens to be heated by a furnace, the boxes should be put in as cool a corner as can be found, and wherever the atmosphere is dry it may be necessary from time to time to sprinkle the sand a little, or to keep the boxes closely covered with paper.

A vegetable of which rabbits are exceedingly fond and which can be grown with the greatest ease, and yet which is almost unknown in American gardens, is Witloof Chicory. It is really an improved form of the 
common wild chicory, and is extensively forced for winter use across the water. In times past great quantities of this forced Witloof, or as it is called in the restaurants, French endive, were sent to this country from Belgium, but of course that trade was entirely upset by the war. Owing to the lack of importations, a number of American gardeners began to grow it in a commercial way, and roots can be obtained in the fall. There is no reason, though, why any amateur shoudn't grow this salad vegetable in his own garden, and it is only necessary to plant seed in the spring, to thin the young plants so that they will stand a foot apart, and to dig up roots when fall comes, keeping them in a cool place until they are wanted.

If the roots are buried in boxes of earth, with the crowns just at the surface, and the boxes kept in a warm place and the earth occasionally moistened, white, crisp shoots will soon start, and when a few inches high can be cut for the table. The heads will grow more compact and straight if three or four inches of sand be placed over the crowns in the box. The shoots will come right up through this 
sand, but should be cut just above the roots. They will grow up two or three times.

While this salad is highly prized for table use, it is an excellent food for rabbits of all ages. In order to get the sprouts white they must be grown in a dark place, or a second box be upturned over the one containing the roots. The rabbits are not particular about the color or delicacy of flavor, however. They are just as well satisfied with the green leaves which come when the plants are grown in the light indoors, and the larger leaves which are produced in the open outside. The leaves make a rank growth, and the plants come up the second year, so that this is a particularly easy vegetable to cultivate. It should be watched, however, and not allowed to run wild or it may turn into a weed.

Another good form of green food is Curly Scotch Kale. The particular advantage of this lies in the fact that it comes very late in the season, not being affected by early frosts, and often lasting until Christmas, even in the northern states. A few plants provide a large amount of food. Kale, like cabbage, makes ill smelling hutches. Dwarf Essex Rape, such 
as is commonly used for hogs and chickens, is an easily raised though less valuable food, perhaps, for rabbits. It can be obtained very quickly in the spring, which is a point in its favor.

New Zealand spinach is another good vegetable for the period lasting from mid-summer to late fall. It is especially to be prized in a small garden because a single short row will be sufficient. If only the outer leaves are harvested, it will continually renew itself, providing a continuous supply of greens. Rabbits are also very fond of celery tops. Corn stalks may be fed green and cured but should not be fed if moldy.

While most vegetables should be fed raw, - potatoes must always be cooked, if they are to be given to rabbits at all. They contain too much starch in a raw state. They are not relished by the rabbits when raw, anyway, but are eaten fairly well when cooked, especially when mixed with a little bran or other grain. It will hardly pay to grow potatoes for rabbits but the small specimens, many of which are usually produced along with the large tubers, constitute a sort of by-product which can be 


\section{WHAT AND HOW TO FEED 89}

used profitably for feeding the rabbits. Certainly an occasional feeding of warm, cooked potatoes, mixed with bran, is relished, and has a beneficial effect.

So much for garden vegetables for rabbit feeding. More than usual attention has been given to this phase of the subject because it is felt that amateurs and even commercial rabbit growers can greatly reduce their expenses, especially in times when grain is high, and thus make rabbit raising more profitable by growing a large proportion of the food needed to keep them in good condition. It is not to be assumed, though, that the amount of grain required for a few rabbits constitutes a heavy item of expense. It is true that some people raise their rabbits wholly on green food and vegetables with the addition of hay. Less rapid growth is made, though, and the rabbits are less suitable for meat purposes, the flesh being too soft. A certain amount of grain is almost indispensable for good even growth, and to improve the texture of the flesh. At the same time an excess of grain is objectionable, making the meat too hard to be wholly satisfactory. Experienced breeders like to use 


\section{PRACTICAL RABBIT KEEPING}

more or less cooked potatoes and various root crops to develop meat of the best quality.

It is reasonable to suppose that the rabbit keeper will use the kind of grain which is most plentiful and consequently the cheapest in his section. Oats are considered by most rabbit keepers the best grain, but there is no good reason for giving them precedence over barley, wheat, or even corn. Whole corn is eaten readily by the larger rabbits and boiled corn makes an excellent ration. Some rabbits have a habit of husking the oats given them, and oftentimes hulled oats are preferable to any other kind. For young stock crushed oats are to be preferred as more easily digested. There is no reason why the rabbit keeper should not have a small hand mill and prepare his own oats.

The use of moist mashes containing bran, corn meal, barley meal, and possibly a little gluten meal has been much discussed in the pet stock magazines, with numerous arguments pro and con. There seems to be no special reason why they shouldn't be used, and yet no very good reason why they should, except that the preparation occasions more labor than 
that of dry grains, and results are no better except as a sort of pick-me-up during the winter season when a rabbit is run down, perhaps from excessive breeding.

Hay is absolutely necessary. It should be bright clean hay, too, alfalfa, clover or timothy. Quite commonly a little hay is put into the hutch for bedding, and the rabbits eat some of it. It is well, though, to have a rack on the wall at one end of the hutch where fresh clean hay can be put. Such a rack is easily made from a few laths or from poultry wire with a two-inch mesh.

When it comes to milk, one again finds arguments for and against its use. Sometimes the rabbits themselves decline to eat milk at all, but usually they seem to relish it. Whatever may be said, experiments seem to show that dry bread soaked in milk makes an exceedingly beneficial food for does just before and after their young are born. It isn't necessary to develop any of the elaborate feeding formulas sometimes recommended at this time. A healthy doe will get along very well on oats and hay, if given a supplementary feeding of carrots and other succulent roots. Neverthe- 
less bread and milk help to keep the doe in better condition and better flesh during this trying period. A better flow of the lacteal fluid seems to be created also, which is important if the litter is a large one.

Beginners often ask if table scraps cannot be fed to rabbits. They can be given in moderation and with limitations. Meat should be withheld, although some rabbit keepers advise the use of fresh chopped beef. Rich, sweet foods should be kept out of the rabbitry, but pieces of stale cake and of dry hard bread may be fed without fear. All that has been said applies to rabbits that have reached the age of three or four months.

With young stock the feeding of green food must be done very carefully. For the first few weeks it is best that they have none at all. After that a little may be given, and the amount increased gradually, but if the rabbits are seen to be growing big and pouchy under the stomach, the amount of green food should be reduced or cut off entirely, because the condition known as pot-belly is being produced. This is a common trouble with youngsters which have too much food of any kind, and espec- 
WHAT AND HOW TO FEED 93

ially an excess of green stuff. When the youngsters first begin to come out of the nest they should not be allowed to feed on the rations provided for the mother. A board may be set in front of the nest box at feeding time, or the doe may be removed and fed in another hutch.

Under ordinary circumstances two feedings a day are sufficient, and they should be as wide apart as possible. Most rabbits, and especially Belgian hares, are particularly active after nightfall, sleeping much of the day. The best time to give them their heavy meal is just before dusk. Then it is that their grain ration should be set before them. The amount will vary with the size of the rabbits. Belgian hares require about a handful of oats at a time. Giants take a little more. All rabbits with young require about twice as much as at other times. A little hay should also be given at night. In the morning vegetables and hay can be fed. It is important that no food be left in the hutch for very long except hay. Bread and milk, or anything that is likely to sour, must be removed promptly and the dishes carefully scoured. Green food must 


\section{PRACTICAL RABBIT KEEPING}

not be left in the hutch after the rabbits have had their fill. It is always better to keep the animals a little on the hungry side, rather than to overfeed them. Probably over-feeding has caused more losses than any other one thing. A breeding doe just before kindling and while nursing her young should have three meals a day without fail.

Rabbits, like most other animals, seem to require a small amount of salt. Some breeders keep a little rock salt in the hutches at all times. Others think that the animals get an excess when this is done, and prefer to mix a little salt at intervals, say twice a week, with a mash or perhaps in their oats. What are called salt spools are now on the market. They are simply round cakes of specially prepared salt with a hole in the middle by which they can be spiked to the side of the hutch or suspended by a cord.

When the rabbits are feeding freely on green stuff, they do not require much water, but at other times should be watered at least twice a day, being given all they can drink. This is the best plan in the winter time, but in summer it is more humane and easier to keep 


\section{WHAT AND HOW TO FEED 95}

water before the animals at all times. Special water dishes not easily tipped over are on the market. Butter crocks are sometimes used, and can be kept from being overturned by the use of four upright spikes or wooden knobs fastened to the hutch floor. Sometimes metal dishes are used and fastened to the side of the hutch. Any dish which is loose, unless very heavy, will be overturned by the rabbits and the contents spilled. As has been said in another chapter, does about to kindle should have water at hand at all times.

Many patented foods or proprietary mashes are on the market. Their use is not recommended. Some of them may be valuable and cost no more than ordinary grain rations, but many contain stimulative ingredients which in the long run are injurious. 


\section{Chapter X.}

\section{SIMPLE RULES FOR BREEDING}

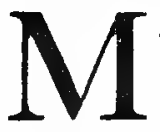

ANY rabbit books are devoted very largely to the subject of breeding. That is because they are written for the benefit of the fancier. It is necessary to know all about the breed which one is handling if one's aim is to produce exhibition stock. There are little matters in connection with the breeding of one kind of rabbit which may not apply to that of another. When one is raising rabbits for utility purposes, it isn't necessary to be so particular, but there are certain fundamentals which must not be overlooked if success is to be won.

The fancier who is trying to secure high class rabbits which will win in a show room or bring a long price when sold often limits the number of litters produced by each doe to two a year. On the other hand, some breeders who are working wholly for meat production, 


\section{SIMPLE RULES FOR BREEDING 97}

allow their does to breed six or even more times a season, perhaps breeding them when their young are a few weeks old. The does themselves are turned into meat before they are two years old. Between these extremes comes that of the average breeder who aims to produce some rabbits good enough to sell for breeders or perhaps to exhibit, but whose main object is the rearing of utility stock. Such breeders obtain four or possibly five litters a year, and destroy some of the young as soon as born if the litter is larger than the mother can easily care for. This is a logical and intelligent plan. The does are not weakened as when they bear an excessive number of young, and the youngsters themselves have sufficient stamina to give them a good start in life.

The breeder whose mind is fixed wholly on meat production pays little attention to the general appearance of the rabbits which he uses. He simply tries to have them vigorous and of good size. It is a good plan for the amateur, though, to use some care in selecting his breeding stock, trying to get as good a class of animals as possible without including those 


\section{PRACTICAL RABBIT KEEPING}

which have been weakened by being bred too fine. For years there will be a sale for breeding stock, and the average amateur can dispose of a certain number of animals at a better price than when they are turned into meat. Meat breeders have size as their standard, and they try to choose rabbits for breeding stock which have broad backs and heavy hind quarters, because like produces like, and the young of such animals will make good looking rabbits when dressed. It is important to choose a large buck, for with rabbits as with poultry much depends upon the male side of the line. The buck always ought to be as good as or better than the doe. It is thought by some breeders that extra good meat animals are obtained by crossing, using Flemish Giants. These Giants crossed with New Zealand Reds or with Belgian hares produce excellent meat stock. The result of these crosses should not be used for breeding, however, at least as regards the bucks. Good results may be obtained by breeding a thoroughbred buck to a crossbred doe.

It is folly to breed immature animals. The doe may be ruined and the young are pretty 


\section{SIMPLE RULES FOR BREEDING 99}

certain to be weak, especially if the litter is a large one. Maturity depends somewhat upon the way in which the animals are cared for, but does of the smaller and medium size breeds are ready for mating when six or seven months old. It is better to wait two months longer with larger breeds, like the Flemish Giants.

Of course the time of the year must be taken into account. It is best when possible to start breeding in the spring, as that is the most natural time. Moreover, it is much easier to care for the youngsters after the weather begins to get warm. When rabbits are born in cold weather, extra care must be taken to keep the hutches warm and free from drafts or dampness. At the same time, artificial heat, except in the case of lop-eared rabbits, is not desirable. That being the case, many breeders allow their animals to rest during the winter months, or until February. Breeding early in the year has some distinct advantages, one of which is that the youngsters get well grown before hot weather comes. It has been found that rabbits born before May are usually more vigorous than those which come along later in 


\section{IoO PRACTICAL RABBIT KEEPING}

the season. This is an important point, especially to the utility breeder.

Breeding stock can be kept for several years before their powers wane. In France, where rabbit breeding has been made a science, the breeding stock is considered to be at its best between the ages of eight and fifteen months. Exhibition rabbits may be kept for breeding purposes up to four or five years, but when meat is the object desired, it is best to dispose of them earlier, before the meat gets too tough. Rabbits have been known to breed up to ten years and even when older.

Reading the usual flamboyant advertisements about the remarkable fecundity of rabbits, one infers that the young keep coming along in an uninterrupted stream the whole year around. The truth is, though, that breeding is not easily affected after the beginning of August and up until late winter. At that time the rabbits are molting and breeding is not recommended in any event if one is looking for high grade stock. It may be forced when meat is the object. Old-time breeders say that feeding peas that have been soaked in water helps to induce breeding, the peas being 


\section{SIMPLE RULES FOR BREEDING IOI}

given for about a week in addition to the other feed. Feeding a little whole corn and also apple-tree bark will cause some does to get into breeding condition. Various other practices are recommended, but their value is doubtful.

When a doe is to be bred, it is always best to remove her to the hutch occupied by the buck. This seems to be the concensus of opinion among experienced breeders now. If the buck is put into the doe's hutch, she is likely to resent his intrusion and offer combat. Experienced breeders learn to know when to handle a doe, especially in the spring, taking note when she becomes restless and stamps around her hutch. The beginner, however, will have to try her. She should be lifted gently and placed in the buck's hutch. Some breeders leave the animals together for several hours or over night, but this is not a wise plan. If the doe hugs the floor or runs wildly around the pen, she should be removed in a few moments, and tried again the next day, this being kept up as long as necessary. In spring, especially, the doe is ready for the buck at periodical intervals of about five days. If the time 


\section{I02 PRACTICAL RABBIT KEEPING}

is right she will make no resistance. It is important for beginners to understand that it is often difficult to induce a virgin doe to breed; sometimes many trials have to be made before she is safely bred.

It often happens, though, that a doe is removed before she has been bred when she is handled by a novice. Then at the end of the month a complaint may be made that the buck is useless. The animals should always be watched, and when the buck falls over on his side or backwards, the owner will know that service has been complete. One service is better than several, and in a few moments the animals should be separated. A buck should not be used oftener than two or three times a week.

After the doe has been put back into her hutch she should be kept as quiet as possible until her babies come. They usually arrive in thirty days, but sometimes are delayed for a day. The does must have a special nesting box which may be a permanent part of the hutch or a smaller box with an opening a little larger than the doe cut into one side. This opening should face away from the light. It 


\section{SIMPLE RULES FOR BREEDING IO3}

may be a good plan to bore a few holes in the sides of the box for extra ventilation. Soft hay is the best nesting material, and an abundance of it should be supplied. Sometimes, though, a doe will pack her nesting box too full of hay. The nest is lined with fur which the doe tears from her body. The nest is usually made ready a few days before the young are due. It sometimes happens, though, that nest making is commenced within a few days after service. When that occurs it can be taken as an indication that the doe was not successfully bred. She should be introduced to the buck again at once in order to avoid the loss of three weeks' time or more.

The birth of the youngsters usually takes place easily, but the doe becomes very thirsty and a supply of fresh water should be kept in her hutch. Oats should also be kept at hand for several days before the event takes place. Sometimes a doe develops an abnormal appetite and devours her own young. This unpleasant happening can be prevented oftentimes by hanging a piece of salt pork in the hutch where the doe can readily obtain it.

After the doe emerges from the nest box, a 


\section{I04 PRACTICAL RABBIT KEEPING}

careful but cautious examination should be made, and the dead rabbits removed from the nest. A litter often runs as high as ten, and may reach fifteen or sixteen. Now a rabbit has only eight teats, and sometimes in the case of the Belgian hare, only six. If there are any excess young remaining alive, the weakest looking of the lot should be destroyed. It is much better to have a doe raise six or seven robust, healthy youngsters than ten or a dozen that are weak and undernourished. With fancy stock, a foster-mother is sometimes used for part of the litter. Dutch does are considered especially good foster-mothers. Quite often rabbit breeders are told that they should have several does produce their young at the same time, so that the litters can be divided up. This is a much more difficult matter to arrange, however, than it sounds, and seldom can be worked out satisfactorily except on a plant where a large number of rabbits are kept.

Being blind and naked when they are born, the young rabbits are perfectly helpless. They make rapid growth, though, and in less than three weeks are to be seen poking their heads 


\section{SIMPLE RULES FOR BREEDING IO5}

through the nest opening. Then they begin to make furtive dashes into the light, beating a hasty retreat when anyone appears and tumbling over themselves in a mad dash to get out of sight. In four weeks or a little more, they lose most of their shyness and are to be seen playing about the hutch.

Does differ in individual traits; some are very docile and tame, while others are nervous and easily excited. With animals of the latter characteristics, visitors should be kept away for some days after the young have been produced. It may be wise in such cases to postpone examining the nest for several days. A French writer says that rabbits habitually suckle their young very early in the morning, and again between six and eight o'clock in the evening, but occasionally we find a doe nursing her young during the day. Obviously they should not be disturbed at this time. If a doe is frightened she is likely to drag her babies into the open hutch, as they attach themselves very firmly to her teats. She will seldom carry them back again, and they are likely to perish. Most breeders know what it is to find a collection of little dead rabbits scattered 


\section{Io6 PRACTICAL RABBIT KEEPING}

around the hutch at some time or other. It always makes it easier to examine the nest by giving the doe a little green food to distract her attention.

In a rabbitry where a number of animals are kept, it is advisable to maintain a stud book. In fact, a book of this kind is absolutely necessary when a business of any proportions is carried on, unless some kind of record blank is attached to each hutch. The point is that the breeder must know exactly when his does are to litter, or to use the common expression among rabbit breeders, to kindle. This can be known only by keeping a record of the dates on which the does were bred. The stud book or record sheet should also have a place for the number of young produced in each litter, and other information.

There is a bugaboo which looms large on the horizon of many rabbit keepers, both amateurs and those in the professional class. It relates to what is called in-breeding. Most of the rabbit books gotten out by commercial growers lay great stress on the danger of the inter-breeding of rabbits having a close blood relationship. Much of this danger is purely 
SIMPLE RULES FOR BREEDING 107

imaginary. With all kinds of animals inbreeding has been practiced continually for many years to fix a type or to secure high grade exhibition stock. This is true of rabbits as it is of horses and cattle. Now in the production of animals purely for meat purposes, in-breeding is neither desirable nor necessary. In fact, cross-breeding seems to give better results when the cross is made only once. The truth is that the average breeder does not understand what is meant by the terms. In their book called "Rabbit and Cavy Culture," Messrs. Roth and Cornman devote much space to the consideration of this whole subject. The following is a brief and trenchant explanation of the terms mentioned:

"Cross-breeding is the mating of two thoroughbred breeds of diverse species, as the Hackney and Trotting horse, Alderney and Holstein cow, Bulldog and Hound, Belgian and Flemish, or Dutch and Silver, etc. Subsequent matings of such offspring can be lineor in-bred.

"Line-breeding is mating individual specimens of a breed when interruption in relationship exists by remoteness. 


\section{PRACTICAL RABBIT KEEPING}

"In-breeding is the mating of close related ones of the same species.

"With regard to this latter form of breeding the United States Bureau of Animal Industry has bred brother and sister mated in sequence order down to the Ioth generation, cavies being the example, and regarding which Dr. Schroeder writes, 'We have found nothing to indicate that the intensest form of in-breeding, carried on for nine or ten generations, is injurious. That for the preservation and perpetuation of especially fine points, and for the establishment of new breeds through the selection of naturally occurring mutations we are practically forced to resort to in-breeding.'

"One factor stands out pre-eminently above all others in its relation to breeding, no matter along what line the latter is practiced-that of health, and the possibilities from heredity. One should never mate specimens containing physical defects, not when affected with disease whose transmission is known to influence the offspring. I am not alluding to physical faults, not to diseases that are curable by proper treatment. These will not transmit 


\section{SIMPLE RULES FOR BREEDING IO9}

defects; but in the event of in-breeding, essentially close in-breeding, physical defects will likely be greatly accentuated, and constitutional disease all the more."

The fancier must understand line-breeding, but unless he practices restraint, he may be tempted to go too far and use animals lacking in stamina, thus producing a strain that is physically degenerate.

It is considered wise to mate an old doe with a young buck, and vice versa, rather than two old rabbits, however good. 


\section{Chapter XI.}

\section{RAISING THE YOUNG STOCK}

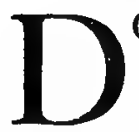

OES usually wean their young when the latter are about six weeks old, although a little longer time may be allowed in cold weather. It isn't necessary to remove the youngsters at once, however, as they can be left with the doe for some time, unless the hutch is over-crowded. When six weeks old, though, they can take care of themselves, and probably will grow faster than if left with the doe. Sometimes the youngsters are removed at an earlier date, as they are seen to be eating the food given the mother, but this is a serious mistake. It is important to give the youngsters room enough to run around and exercise freely. With Belgian hares rather long hutches are sometimes used, the hutch containing hurdles over which the youngsters are forced to leap. This is supposed to develop the long, racy body type which is desired in 


\section{RAISING THE YOUNG STOCK I I I}

rabbits of this breed. It is even more necessary in the case of young rabbits than mature animals to keep the hutch clean and sanitary, the floor being covered with sawdust, leaves, hay or peat. Filth of any kind fosters diseases which are difficult to eradicate.

The feeding of the young rabbits is an important matter, but will be found covered in Chapter VIII.

If the weather is cold, special care must be taken to keep the youngsters warm. The hutch should be in a tight building, and it may be necessary to drop a blanket or some other covering over the front at night. Raising young animals in winter always has disadvantages, except in a rabbitry equipped for the purpose, or in the warmer parts of the country.

By the time they are three or three and onehalf months old, the sexes should be separated. It becomes possible to tell them apart at that age by a physical examination, as described in Chapter VII. If the sexes are left together longer there is danger that the does will be prematurely bred, to their lasting injury. The bucks, too, will begin to fight among themselves. Sometimes bucks that have grown up 


\section{2 PRACTICAL RABBIT KEEPING}

in the same litter can be confined in the same hutch or pen for some time longer, if they have plenty of room. Quarrels are pretty likely to come about, however, and valuable rabbits may be seriously injured, perhaps having their ears torn, or their noses mutilated. Naturally the breeder who is raising utility stock will get rid of all surplus bucks very quickly, keeping only a few of the best animals, so that he can maintain a ratio of one buck to eight or ten does at all times.

Amateurs often find it possible to sell wellmarked young bucks for breeding purposes. The fancier will select such animals as promise to be of special value and let the others go, possibly for meat.

Some breeders seem to think that it is advisable to have small hutches and to keep only two or three young rabbits in each hutch. This, however, is not good policy. The growing stock needs plenty of room, and companionship. It usually is quite possible to unite the does of the various litters.

The meat breeder will find it advantageous to have his males castrated before they are four months old. The flesh of rabbits becomes 
RAISING THE YOUNG STOCK I13

too soft and flabby to be satisfactory if the young animals are kept closely confined. The exercise which they get when romping in large hutches or in yards puts the meat into the best of condition.

With rabbits raised for exhibition, this same method of handling is wise because it puts the rabbits into the best physical condition, which is as important with fancy stock as with utility animals.

If young rabbits when purchased are found to be wild, the reason is that they have not been handled sufficiently. Rabbits that come from large plants are likely to be much wilder than those raised by amateurs with only a small business because the extensive breeders have less time and opportunity for working with and handling their youngsters. At the same time the rabbits must not be worried or tormented. This is an important matter to bear in mind when there are children on the place.

A rabbit that is shrinking and timid, or that is ill-tempered and tries to fight or commences stamping when anyone approaches is not an animal to be desired, however well it may be marked. 


\section{I4 PRACTICAL RABBIT KEEPING}

Between the ages of eight and sixteen weeks, the rabbits usually go through a molt and sometimes become out of condition. If they come from good stock, though, there should be no trouble at all at this time. 


\section{Chapter XII.}

\section{EXHIBITING AND SELLING}

N1 $\begin{aligned} & \text { ANY a man has begun keeping rab- } \\ & \text { bits without the slightest intention } \\ & \text { of ever putting his animals into a }\end{aligned}$ show, but after having become interested in the improvement of his stock, has become an enthusiastic exhibitor. A few commercial rabbit keepers exhibit solely for advertising purposes, realizing that by having prize winners in their hutches they can get better prices for their breeding stock. These are not the men who give the best tone to the fancy. It is the amateur who enjoys a keen competition and loves to associate with fellow breeders and talk over different matters pertaining to their mutual hobby, who is the backbone of the industry. Naturally enough, the showing of rabbits leads to their sale, for people always like to buy from a breeder who has produced prize-winning animals. 


\section{II6 PRACTICAL RABBIT KEEPING}

Of course it is necessary to have first class foundation stock if one is going to show with success, but it is just as necessary to understand the principles of breeding, and the idiosyncrasies of the different breeds. Many points can be learned from books and from discussions, but others must be learned by personal experience. To begin with, one must be familiar with the standard and have an ideal in mind. Then when he has produced what seems to him to be a rabbit worth showing, he must put it into proper condition for exhibition. In many cases preparation has much to do with winning prizes, especially now that competition has become sharp. It is most essential to keep the animals in the best of health, giving them plenty of exercise and feeding them the best of rations, although not in excess. Most breeds should have a sleek, smooth coat to please the judges, and all short coated varieties should be carefully groomed. Mr. C. J. Davies, one of the most noted of the British rabbit breeders, has given the following instructions for preparing rabbits for the show room:

"The best thing to put a finishing gloss on 
the coat is to add a small teaspoonful of linseed to the concentrated food of each exhibit daily for two or three weeks before the show. No advantage is gained by boiling the seed. Whole seed is preferable to meal, as it keeps better and the fancier can see what he is buying. Linseed cake is sometimes used; but as the best cakes only contain about ro per cent. of oil, whereas the whole seed probably contains about 35 per cent., the latter is better value for money spent on it.

"Angora rabbits need regular brushing every day to keep them in show form, and on the day before the show white Angoras and Polish will be the better for a dusting with white prepared fuller's earth. Exhibitors of Polish specially recommend flour thoroughly dried in the oven, with $2 \mathrm{oz}$. blue added to I lb. of flour, as a coat cleaning agent. All such preparations must be thoroughly got rid of with a clean brush or the rabbit may be disqualified.

"Dark-coated rabbits require no real grooming, although some fanciers make a practice of smoothing the coat with the palm of the hand into which a speck of vaseline or 


\section{II8 PRACTICAL RABBIT KEEPING}

a drop of paraffin oil has been well rubbed. It is safer for the novice to content himself with a rub down with a 'Selvyt' or a silk handkerchief, which will do all that is required if the rabbit is as fit as it should be.

"Rabbits suffer considerably from being exhibited, as is proved by the fact that in the writer's experience adults will lose several ounces in weight and growing youngsters fail to add to their weight during the time (and for a few days after) they are away. The obvious moral is not to show valuable animals too frequently.

"Many rabbit breeders, with an entire disregard for the comfort of their stock, send them in boxes which are far too small. A useful size of box for a $5 \mathrm{lb}$. rabbit is 16 in. to I 8 in. long, Io in. wide, and I in. high. Belgian hares and Flemish Giants require much larger boxes, and Polish may be sent in rather smaller ones; but it is wiser to use an unnecessarily large box for a valuable rabbit than to risk cramping it for the sake of a few pence extra on the railway charge. Ventilation must be provided in the form of holes about 4 in. in diameter cut in each end of the box and 
EXHIBITING AND SELLING II9

covered with perforated zinc. A piece of wood screwed over each ventilation hole will prevent the box from being packed so tightly against another package that all air is excluded.

"As several rabbits travel more cheaply in one box than in separate packages, two, three, or four compartment boxes or baskets, furnished with a separate inner lid to each compartment, are used by exhibitors. The box should be well hinged, have a good fastener (preferably a strap and buckle, the strap nailed to the box and passed right round it, as this form is fool-proof), and for comfort in carrying a strap handle on top. Rabbits must not be sent to shows in boxes which are nailed up or inconvenient to manipulate in any way. All railway charges have to be defrayed by the exhibitor. A handful of sawdust should be thrown into the travelling-box, placing thereon a good layer of the best hay procurable. A crust of bread and a good slice of root or apple should be put in and the box is ready for its occupant."

Of course the rabbit breeder will try to enter no animals which have disqualifications 


\section{I20 PRACTICAL RABBIT KEEPING}

such as wry tail or crooked legs, or one that is molting. Animals which give evidence of disease in any form must, of course, be eliminated.

Sales are often made in the show room, and others as a result of the winnings. Naturally the exhibitor will hesitate to dispose of the rabbits which have won for him, but he will gladly have orders for the progeny of his winners. It sometimes happens that zeal to make sales will lead the breeder to misrepresent his stock to some extent. This is a fundamental mistake. No breeder can go on successfully unless he recognizes at the start that honesty is in fact as well as in theory the best policy. Only animals in the best of condition should be sold unless the buyer has first seen them and knows just what he is getting. The stock sometimes sent out to unsuspecting amateurs is a disgrace to the breeders who ship them.

As a means of protection the practice of registering rabbits has been adopted, and only thoroughbred animals are eligible to registry. Registering is done under the direction of the National Breeders' and Fanciers' Association, 


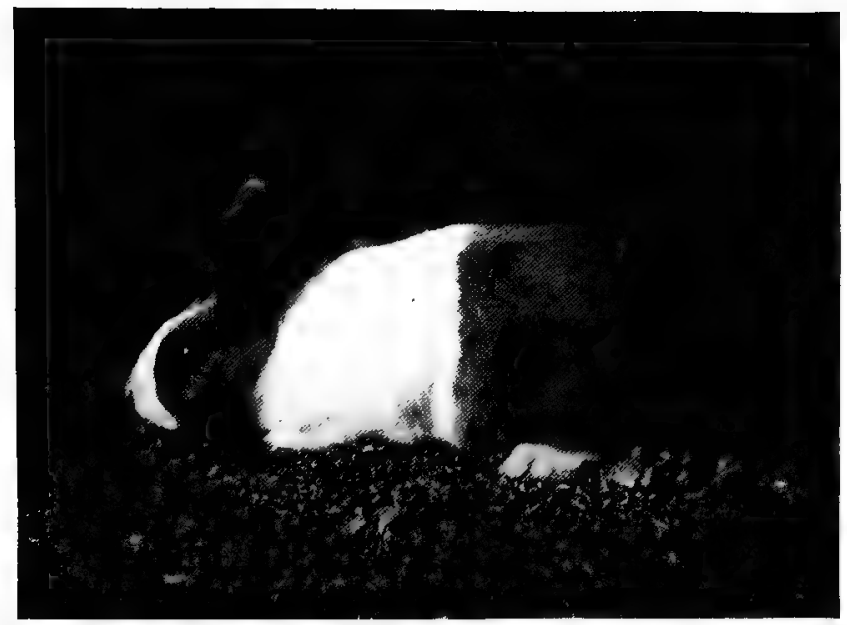

Well Marked Dutch Rabbit

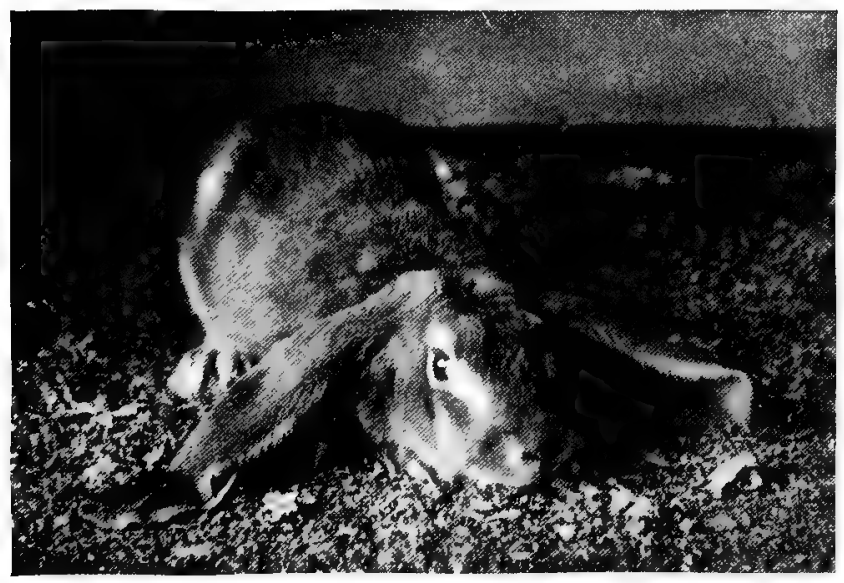

English Lop-eared Rabbit 

EXHIBITING AND SELLING I2I'

which is the leading organization of the United States, and the one with which all societies are affiliated. Registrars are established in different parts of the country. The breeders ship their animals to this man who inspects them carefully, and if they prove satisfactory as to physical features, etc., a registry number is stamped on the ear. When a registered rabbit is purchased, the buyer feels that the animal is practically guaranteed.

It sometimes happens that a dispute arises between buyers and sellers. In that case the question at issue may be placed before a complaint agent appointed for different sections. His decision must be considered final by all members of the National Association.

The fee for registering a rabbit is one dollar, and registrations must be sent to the secretary of the association not later than thirty days after the animal is registered. The pedigree of an animal to be registered must always accompany the application. The pedigree is the ancestral tree of the animal. It should. date back for three generations on each side, the name of each progenitor being given. A pedigree is arranged as indicated below: 
It is, of course, true, as often charged, that pedigrees can be faked, and that this dishonest practice is common. As a matter of fact, fak-

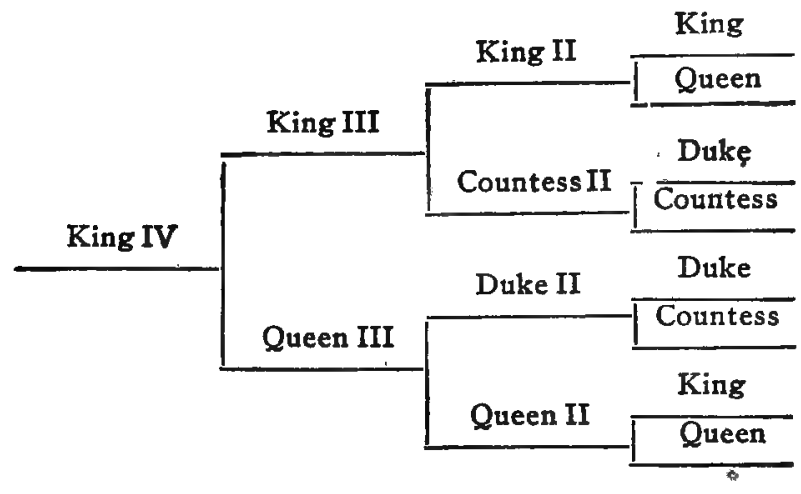

ing is done by fewer breeders than may be supposed, and obviously there is no good reason for opposing pedigrees because a few fakers exist.

The man or woman selling rabbits should keep a card index so that he or she will know the history of every rabbit in the hutches, and the disposition which is made of it. If the seller is wise, he will send a blank receipt to his customer to be filled in and returned. If this receipt states that the animal was received and found to be as represented, there will be no 
ground for dispute in the future. Every order should be acknowledged as soon as received, and filled as promptly as possible.

It is helpful to send out some instructions for the use of buyers who have had no previous experience. A set of rules for buyers printed on small slips of paper can be purchased at a low price from supply houses. These rules include the following:

All stock shall be in perfect condition and free from disease when it leaves our possession, unless stated otherwise in writing.

Any animal dying after it leaves our possession is at the risk of the owner and we are in no way responsible for same.

Stock that is sick, crippled, damaged or a part of it dead when it reaches the purchaser should be accepted and before signing your name on the Express delivery book you should write on the book in ink the nature of the damage or loss; then, immediately write us a letter giving the facts and we will enter a claim against the Express Company and collect for the loss and immediately replace the loss to you and ship same all charges paid. Where shipment is a total loss it should not be accepted.

Use care in not overfeeding or underfeeding your stock. Give them every morning what oats 


\section{PRACTICAL RABBIT KEEPING}

they will clean up in about 45 minutes, also clean pure water. At night give them hay as they are nocturnal eaters and keep at it all night. Filthy water produces worms.

Do not let every Tom, Dick and Harry discourage you. Use your own good common sense. If you need advice, write us for it. Many people are constantly taking the joy out of life and as we want you to be successful we will help you gladly at all times.

When you are ready to sell the stock you raise let us hear from you and we will help you find a market.

To be successful in any new undertaking you must read, study, experiment and stick-to-it until you master your problem. 


\section{Chapter XIII.}

\section{PREPARING RABBITS FOR THE TABLE}

T $F$ the rabbit industry is going to assume as extensive proportions in America as 1 abroad increasing attention must be given to the production of meat. Already that is the phase of the business which appeals most to a large number of people. So far, however, the demand for breeding stock has been so persistent that only a limited number of animals have been available for market purposes. How long this will continue nobody can tell, but it is certain every effort should be made by commercial rabbit.keepers to extend the demand for meat animals as rapidly as possible. Otherwise that demand may not exist in a large way when the point of saturation is reached.

A constantly increasing army of commuters and other people find rabbit meat unsurpassed 


\section{I26 PRACTICAL RABBIT KEEPING}

for the table, and large numbers of rabbits are being raised for private consumption. This, of course, will help to increase the general demand. As it is now, this demand is growing in most of the larger cities, but in the smaller cities and towns there is almost no call for meat in hotels or restaurants. Rabbit meat is served regularly on the Pacific coast, as a matter of course. Many rabbits are also being purchased by dealers in New York. Rabbit breeders in states as far away as Massachusetts and New Hampshire are sending all their surplus stock to the big cities, where they get from I 5 to 40 cents a pound. A few dealers in Boston and other eastern cities are advertising for rabbits. In some places the larger breeders buy up the occasional animals offered by the smaller breeders in their section and make shipments to city dealers. In places where there is a large foreign population, sales are particularly easy to make.

Belgian hare meat can be served in a great number of ways, and is quite as delicious as chicken. There is just one point in the cooking to remember, which is that the meat is rather dry, and must be parboiled or treated 
in some other way to remedy this difficulty. Because this point is not recognized is the reason that rabbit meat is often set down as tough and unpalatable.

It stands to reason that the relatively young rabbit is better than one which is old. At the same time they may be used up to the age of two years. Rabbits three or four months old are especially good when served as friers.

When it comes to killing a rabbit for the first time, the amateur must keep the matter out of his thoughts as much as possible, for the job is not a pleasant one. After a little experience, though, it can be done quickly and without making such an unpleasant impression. If possible kill the animal in the morning before feeding. The best plan is to grasp the animal by the hind legs and then to deal it a sudden sharp blow just behind the ears with the side of the hand or, better still, with a short stick. The point mentioned is particularly vulnerable, so that a very hard blow is not needed. Immediately the jugular vein should be cut, which is done by driving the knife into the side of the neck just below the ear, and the animal hung head down to bleed. 


\section{I28 PRACTICAL RABBIT KEEPING}

Sometimes the throat is cut squarely across.

It is a good plan to have two hooks fastened to a post or the wall at the right height to receive the hind legs. The hooks can be run through the skin between the bone and the tendon. Some breeders cut off the head as soon as the animal has been stunned and cook it for the poultry. The rabbit will bleed profusely for a few minutes in any event, and it is well to have a pan or bucket partly filled with bran to catch the blood. This mixture can also be fed to chickens. Of course if the rabbits are to be marketed, the head must be left on. Private customers, though, will want the animal dressed and cut up before it is delivered, and will not care for the head, unless they happen to come from one of the European countries, in which case they may demand it, for in $\mathrm{Eu}-$ rope the head is commonly cooked and used for making soup stock.

When it comes to dressing the animal, a very sharp knife should be used, but with great care so that the bladder will not be penetrated. The abdomen is first opened by making a six-inch slit through which the entrails may be removed. A gall bag will be found in 
the liver and should be carefully taken off. The lungs, liver, heart and kidneys are left in place. After being cleaned the carcass should be left hanging for a few hours before it is shipped away. It isn't best to soak the carcass in salted water at this time, as is sometimes done, but there is no objection to doing this for half an hour just before the rabbit is to be cooked. No water should be used in cleaning the rabbit, but a damp cloth may be employed to remove any spots of blood which may appear.

The appearance of a dressed rabbit sometimes prejudices people against it when they see it for the first time. Doubtless this prejudice will disappear in the course of a few years, but in the meantime it often pays to cut the rabbit into smaller pieces before delivering it to customers. In his Government Bulletin, Mr. Lantz recommends that rabbits when packed for market should be placed in a basket or hamper having movable slatted trays so that the carcasses may be kept packed in separate layers. Such a hamper permits the free circulation of air, not only on the edge, but also throughout the package, and 


\section{I30 PRACTICAL RABBIT KEEPING}

the carcasses packed in this way reach their destination in an attractive state instead of being in the messy condition so often seen in the wild rabbits marketed in America. Certain it is that a good business cannot be built up unless domestic rabbits are sent to market in a much more attractive condition than the wild rabbits, which always appear in large numbers in winter, and which look far from attractive.

Any cook who is accustomed to prepare chicken or fowl will be able to cook rabbits, and can easily devise many excellent dishes, although the necessity of retaining the juices as far as possible must be borne in mind as already mentioned. Most of the recipes given apply to rabbits which are nearing maturity. Less cooking may be needed for those which are under five months or which are light in weight. It is always well to use plenty of fat pork or bacon in cooking rabbits, as they improve the flavor. As with poultry the meat should hang for at least twenty-four hours before it is eaten. Some people like to have the meat get much riper than that, but there is such a thing as letting it become too ripe. 
If there is too much for the meals of a small family and they tire of eating rabbit so often it can be canned like any other meat and kept in jars until wanted. Rabbit en casserole@and in a variety of ways that will suggest themselves to any woman who has had experience as a cook is a change from the monotonous round of beef and lamb, beef and lamb, beef and lamb through the winter. On the Pacific coast rabbits are often used for making mincemeat, being prepared in the same way as beef.

The following recipes have been gathered from many sources, but they by no means exhaust the possibilities in the way of rabbit dishes:

\section{Rabbit Pie}

For rabbit pie make a rich pie crust, rolled thin for the bottom and sides of the dish and just patted out for the top. Line with a layer of thickened rabbit gravy, one of diced potatoes and one of meat. Alternate until the top crust is ready to put on. Top with a layer of chopped onions and tuck in the upper crust. Score to let the steam escape. Bake in a fairly. 


\section{PRACTICAL RABBIT KEEPING}

hot oven, and just before browning rub with melted butter, set on top shelf of oven and brown quickly.

\section{Creamed Rabbit}

Creamed rabbit is delicious, and left over pieces of meat can be utilized by making a thickened gravy of the liquid in which the rabbit was boiled and adding shredded wheat. Stale bread should be moistened and crisped in the oven and the creamed rabbit poured over the toast.

\section{Baked Rabbit en Casserole}

Lay alternate layers of rabbit and thin slices of bacon, season with thyme, sage, thinly sliced onions, and salt to taste. Fill the dish with water, bake in a slow oven for one and a half hours. A covered baking dish or pan may be used instead of a casserole, and the meat may be boned or not as desired.

\section{Rabbit Fricasee}

Brown some butter in a hot iron skillet. Then fry the hare, previously cut up, brown 


\section{RABBITS FOR THE TABLE}

on both sides. Next cover the meat with hot water and stew until it is thoroughly tender, seasoning it to taste. At the end of the stewing, let the meat again fry brown.

\section{Hasenpfeffer}

Cut each rabbit into eight pieces, the two legs, the two shoulders, and breast and back each cut in two pieces. Wash well, drain, then steep for a few hours in vinegar containing thyme, carrots and onions. When ready take the pieces, roll them in flour and fry lightly in butter. Put them in a sautoir (saucepan) when fried. Now fry some pieces of salt pork, add them to the rabbit, with some flour, moisten with stock, simmer and skim. Then add some button onions, a little thyme, and enough of the vinegar they were steeped in to give a sharp flavor. Simmer till tender and serve.

\section{Sauté of Rabbit}

Use the legs and saddles of the rabbits. Soak them in warm water for an hour, then. 


\section{I34 PRACTICAL RABBIT KEEPING}

drain and wipe each piece dry; season, then roll in flour, fry a light color in butter. Make the sauce in the same pan, boil and skim. Put back the rabbit, add some sliced mushrooms, simmer till tender, finish with the addition of a little sherry wine.

\section{Cutlets of Rabbits, Tomato Sauce}

Roll the legs in a mixture of salt, pepper and powdered poultry seasoning, then in flour, dip in beaten egg and fresh bread crumbs. Place in pan containing melted butter, put in slow oven for over half an hour, or till tender and brown; serve with tomato sauce.

\section{Rabbit Liver and Bacon}

Take two or three livers, cut in small pieces; roll in flour, pepper and salt, drop in boiling fat from the bacon, and arrange on platter with thin, crisp slices of bacon and potato marbles. Garnish with parsley or watercress.

\section{Potted Rabbit}

This is a good way to use old rabbits. Cut the rabbit into small pieces, cook in as little 


\section{RABBITS FOR THE TABLE}

water as possible until meat falls from bone; remove bones and strain liquor. Chop or mash in a mortar all meat, adding a tablespoonful of butter and seasoning-a little cayenne pepper makes a nice flavor-work into a paste, pack tight into jars, and seal tight. 


\section{Chapter XIV.}

\section{RABBIT FURS AND THEIR VALUE}

$T \mathrm{~T}$ would be foolish to undertake raising rabbits of any kind simply for their pelts. 1 If the value of these pelts were as great as some breeders would have us believe, rabbit keeping would be taken up by a host of people immediately. At the same time, rabbit fur has sufficient value to warrant saving the skins from animals which are used for table purposes except in the summer months, when they are in poor condition. As a by-product the pelts of rabbits may be handled profitably.

While the war was on, prices of all furs became unusually high, and a larger demand for rabbit skins was created than had existed before, at least in this country. In ordinary times a vast number of rabbit skins are imported from Australia to be used by hat makers. That source of supply being cut off temporarily, manufacturers became interested 


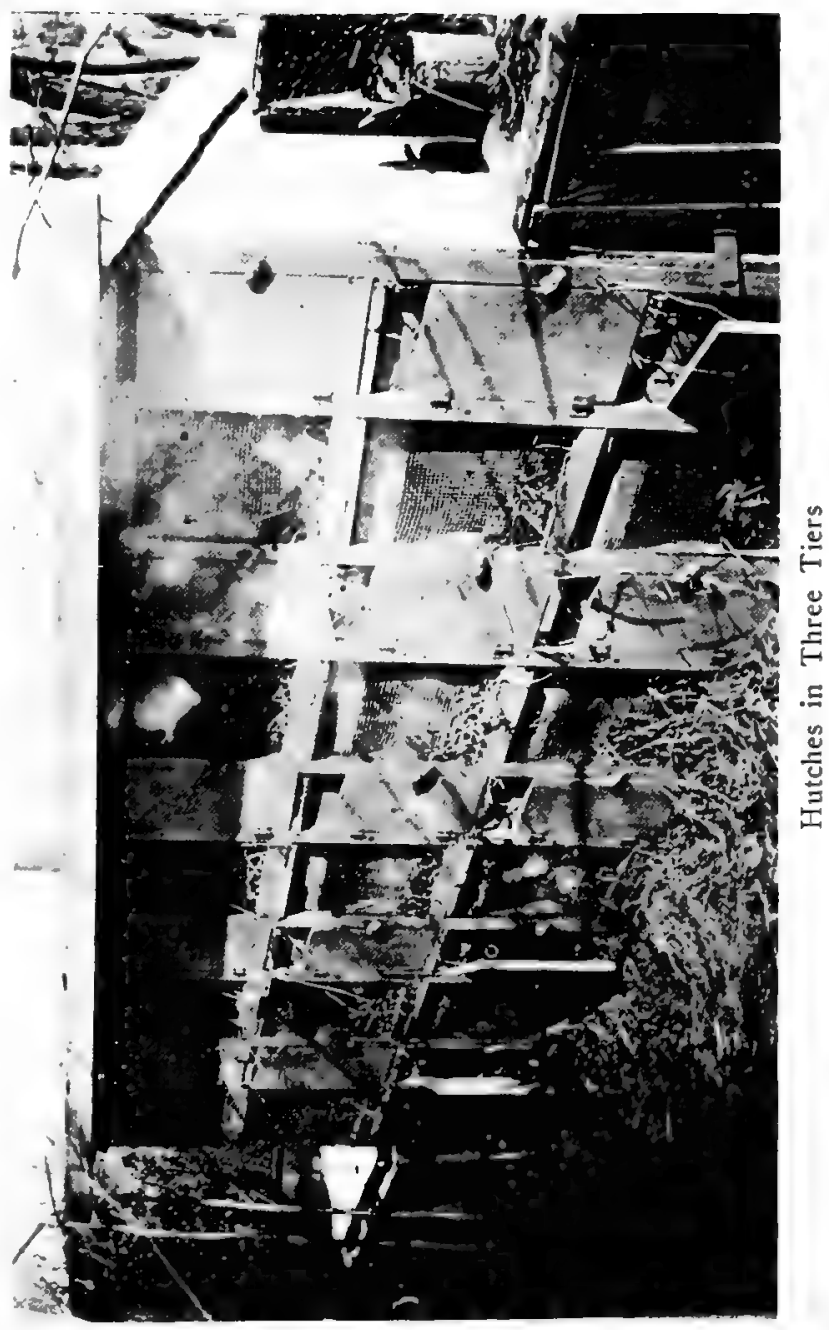





\section{RABBIT FURS-THEIR VALUE ${ }^{3} 37$}

to some extent in local markets. At a recent fur sale in St. Louis, which is the center of the business in the United States, six million rabbit pelts were auctioned off, bringing a total of five hundred thousand dollars. The top price of the sale was $\$ 2.10$ a pound, the best lot averaging seven pelts to the pound. Most of these rabbit sikins came from Australia and New Zealand, only two per cent. having been received from American shippers. It will be seen by this that rabbit skins are in demand even though the price is low. Formerly all the big sales of Australia's output have been held in London, but the business is being established on so firm a ground in this country that it probably can be retained here. That being true, the opportunity for American breeders to find an outlet for whatever surplus they may have will be improved. At these auction sales the buyers are mostly furriers and hat manufacturers from the larger centers.

When one has only a few rabbits, of course, he cannot expect to find a ready market for the pelts, as dealers always like to buy in large lots. Now, however, leading rabbit keepers 


\section{I38 PRACTICAL RABBIT KEEPING}

in various parts of the country are beginning to collect skins from smaller gtowers with whom they do business. Then when they have enough to make a good sized shipment, they consign it to a dealer or wholesale buyer. Of course an extra profit has to be made along the way when this plan is followed; yet sometimes as much as $\$ 1.50$ can be obtained for the pelt of a large rabbit of good color say a white or a black Flemish Giant.

Another very good practice is growing up. Furriers with large plants are advertising to tan skins supplied by rabbit raisers and to make them up into ladies' and children's fur sets, men's caps, gloves and so forth. This is an excellent way in which to obtain a set of furs cheaply. Twelve good sized skins will make a large cape, with a high storm collar, and a fair sized muff. The price for tanning the skins and making up this set, including a lining of Skinner satin is quoted as \$12.00. A fur cap such as farmers delight to wear can be made from four skins at a cost of $\$ 4.00$. The same price is charged for making up a pair of fur gloves with gauntlets and lining them with heavy fleece. These gloves have 


\section{RABBIT FURS-THEIR VALUE I39}

horsehide palms and require five skins to make. It is very probable that this branch of the industry will be extended. It will appeal especially to amateurs who taise only a few animals. Of course the skins will not be those of the best stock, for good breeders are worth much more than their meat and fur.

Naturally rabbit skins will never have a value equal to that of the high class fur bearing animals. For a long time, though, they have brought much more than their original price when sold under some such name as Electric Seal, Nearseal, or Coney.

The whole skins are used for making up these cheap furs, but the hat makers use only the hair, which is cut off, then ground, and put through a process which produces the felt of masculine head gear. It is to this market that rabbit keepers in general should look for their profits in the long run. An almost unbelievable quantity of rabbit skins designed solely, for hat making have been brought from Australia in the past. The skins of rabbits raised in America are just exactly as good for the purpose. It is only a question of getting large enough lots to tempt the buyers. 


\section{I40 PRACTICAL RABBIT KEEPING}

On the Pacifc coast there are many women who engage in the keeping of rabbits either commercially or as a side line. Some of these women have learned how to cure and tan the hides, and are making up fur garments, either for their own use or to sell. It is not difficult to learn to do this work, and there is always a sale for the furs, even though the price is not high. The skins are easily cut to the right shape by being tacked to a flat board, the pattern then being marked out on them with a pencil. A sharp knife is used to make the cutting, being preferable to scissors. If the cutting is not made very deeply and the pieces are pulled apart, the hairs will not be cut, and will have a better appearance. For sewing the furs a baseball stitch or an over and over stitch is used, the seam being then pressed flat. The edges can be finished by running a piece of cloth around them, turning it over and fastening it firmly to a thin piece of cotton over the skin. Of course any kind of lining can be used. It seems as though this might prove a profitable industry for women, especially if furs continue to remain as popular as they are now. 


\section{RABBIT FURS-THEIR VALUE I4T}

Doubtless more attention will be paid by women doing this work to the production of rabbits especially valuable for fur. That means those in solid colors, for when rabbit skins are dyed, they do not wear so well, perhaps because the dye rots them. Such breeds as the Himalayan, the English, the Black and the White Flemish, the New Zealand, the Blue Imperial, the Checkered Giant and the Silver can be used without being dyed. The so-called Siberian hare is considered especially valuable when black furs are wanted because of the even color. Some black rabbits have patches of brown which reduce their value.

If the skins are to be salable, they must be obtained when they are in the best condition. During a molt, of course, they are worthless, unless a market can be found for them at a glue factory. The skins are at their best in the winter, of course, say between October and March, and rabbits which are kept in out-ofdoor hutches are apt to develop a better quality of fur than those which are housed in warmer quarters.

Getting off the pelt is not a difficult matter 


\section{I42 PRACTICAL RABBIT KEEPING}

after one has had a little experience. Sometimes they are removed "cased" and sometimes they are split down the middle so they can be taken off flat. Cased skins are preferred when they are to be sold to fur makers. To go about removing the skins, hang up the rabbit as soon as it has been killed, attaching cords to the heel tendons of the back feet. When dressing the animals for meat and considering the skins of but little value, the rabbit keeper usually makes a cut down the belly the whole length of the skin. When the pelt is to be remaved whole, more careful work must be done. First cuts are made down the inside of the hind legs and to the base of the tail. This cut should extend across the vent and the tail itself 'should be slit. The skin is cut around the legs just above the toes, although sometimes when the feet are especially good the toes and nails are left on. Then with a good strong pull the skin can be rolled down over the body and pulled over the head wrong side out. Sometimes certain ligaments will hold the skin, but can be cut away with the knife. Of course it will be necessary to cut off the forefeet. Then whatever adhering flesh or fat may be seen 


\section{RABBIT FURS-THEIR VALUE I43}

should be removed with the knife. After a little practice this work can be done quickly and easily.

The next step is to cure the skins, which is done by covering the flesh side carefully with salt and letting them stand for three or four days in order that all the moisture shall be dried out. It is best to keep them in a fairly cool place. Then the skins will be ready for tanning. This work is made easiest by using a commercial tanning preparation, such as may be advertised under the name of Easytan or something of the kind. The cost is little, and results are almost certain to be satisfactory. However it is quite possible to make one's own tanning mixture. A formula which has been found to work well is made up as follows :

5 gallons of water

4 pounds of common salt

2 ounces of fluid sulphuric acid.

The salt is first dissolved in the water and then the acid added, care being taken not to inhale any of the fumes. As the acid will eat into metal, it is best to use a wooden or fibre tub or bucket. 


\section{I44 PRACTICAL RABBIT KEEPING}

It will be found advantageous to wash the skins thoroughly before they are put into the tanning mixture, using lukewarm water and a little soap, with perhaps some ammonia added. The skins will need to remain in the tanning fluid for from one to three weeks. When properly cured they should show white when stretched over the fingers. It is important to wring out all the moisture possible after tanning has been completed, and to dry the pelts in the open air, but in a shady place. Then they may be stretched with the hands or rubbed over the edge of a table or a board to. make them soft and pliable. They should"not be absolutely dry for several days, this stretching and working being undertaken in the meantime. A properly tanned skin should be both soft and white. If either condition is lacking, it indicates that it was not left in pickle long enough.

Sometimes furs are greasy and never will be satisfactory unless cleaned, no matter how well they may be tanned. If cleaning is needed it can be done with gasoline or benzine.

Occasionally it is found advisable to work a little Neatsfoot oil into the skin after it is 


\section{RABBIT FURS-THEIR VALUE 145}

dried, to keep it soft. Sometimes yellow ochre is mixed with the Neatsfoot oil to impart a shade of tan to the skin.

In France skins are turned inside out and carefully filled with hay or straw and then hung up in the sun or in a current of air to dry and cure.

When arrangements have been made with a furrier or hat maker to take one's pelts, it may not be necessary to tan them. If they are dried and then packed in a tight box containing moth balls or naphthaline until a considerable number have been obtained, they will keep in good condition. 


\section{Chapter XV.}

\section{WHEN RABBITS ARE OUT OF CONDITION}

\section{1}

THERE would be few ailments among rabbits if the animals were always kept in clean, sanitary quarters, free from dampness and not over crowded, and if they were not fed too heavily. In other words, nearly all of the troubles which develop among rabbits are due to improper care, or perhaps I should say, to lack of care. The two most common ailments are snuffles and slobbers.

Slobbers.-Slobbers most commonly develops among young animals, especially those which are in crowded hutches and which are overfed with green stuff. Undoubtedly it is the cause of greater mortality among young rabbits than anything else. Slobbers is particularly likely to appear between the ages of four and six months or just as the youngsters 


\section{RABBITS OUT OF CONDITION ${ }_{147}$}

are weaned. Its presence is indicated by wet fur around the mouth, and matted fur under the chin. Usually, too, the front feet are found with matted hair where the animal has rubbed the drool from its mouth.

Salt is commonly considered the best cure. Sometimes it is rubbed on the feet and into the mouth. A pinch of salt may be added to a mash. Often a piece of rock salt placed in the hutch will be licked. The use of cooked food for a few days is recommended. Of course all green food should be withdrawn. One remedy recommended consists of a few drops of muriatic acid in the drinking water. There should be just enough to make the water taste slightly tart. Twenty drops of a mixture comprising spirits of nitre and spirits of juniper in equal parts is another remedy. It is to be given two or three times a day in a little water.

Snuffles.-No other trouble which develops in a rabbitry is more common than snuffles, although exactly what is meant by this name is a question upon which rabbit keepers do not agree. Some consider it nothing more than a severe cold, while others call it a pulmonary 


\section{I48 PRACTICAL RABBIT KEEPING}

and chronic disease. In any rabbitry where the animals are heard to be continually sneezing and are to be seen rubbing their noses with their paws, trouble of this kind is to be suspected. One should go slow in buying rabbits from such a place. There is a constant discharge of mucous which is carried to the feet and causes the hair to become badly matted and wet.

The first step towards a cure is to keep the animals in the open air. Indeed, snuffles is not likely to develop where the ventilation is perfect, unless the hutches set on the ground or become damp from some other cause. The writer once had a large number of young animals kept indoors afflicted with snuffles. Although it was winter, he fenced in a considerable piece of ground outside, provided large boxes filled with straw for the animals to burrow in, and turned the rabbits loose in this enclosure. Within a few weeks, all of the trouble had disappeared, and the rabbits were as frisky and as happy as a rabbit well can be There is this to remember, that snuffles, while easily eradicated at the start, is very hard to get rid of after it becomes well established. 


\section{RABBITS OUT OF CONDITION I49}

The remedy most commonly recommended is tincture of aconite, to be given in drinking water or in milk. Three drops to a quart is about the right proportion. Bluestone sprinkled over the oats has been recommended, and often an antiseptic is used for cleaning the nostrils, something like Wick's salve, which one rabbit judge endorses, being used in preference to a solution of carbolic acid or anything of that kind. Hike antiseptic is also used for this purpose. An English breeder recommends dropping eucalyptus oil on the sawdust on the floor of the hutch. The paws as well as the nostrils should be kept clean. Sometimes a cold runs into pneumonia which is usually fatal.

Ear Canker.-This is a somewhat common trouble, especially among the larger breeds and in commercial rabbitries. It is indicated by a scab on the inside of one or both ears. The scab is produced by a small insect which bores into the flesh. It is not a difficult trouble to contend with, and usually can be eradicated by using a few drops of some ear canker remedy, of which several kinds are on the market. It is well to remove the scabby sub- 


\section{I50 PRACTICAL RABBIT KEEPING}

stance with a somewhat pointed but blunt stick. Lukewarm water will aid in removing this incrustation. Vaseline is also used. A soft sponge should then be used to wash out the ear. Boric acid is sometimes applied after the ear has been cleaned, and proves a sufficient remedy if repeated daily for some time.

Pot Belly.-Over-feeding, and especially the feeding of green stuff, is the cause of pot belly, which often appears in young rabbits, especially those under three months old. The trouble is indicated by the distention of the stomach. Naturally the first step in relieving the rabbit is to stop giving green food. Indeed, it is wise to withhold all food for twenty. four hours. In a bad case a small dose of castor oil may be of benefit. An occasional drink of scalded milk may be given. Flowers of sulphur is considered a remedy, a pinch being put into the oats each day. If pot belly is allowed to continue it will kill the rabbits, but is not likely to develop at all if but little green food is given the youngsters.

Paralysis.-It is hard to tell just what causes paralysis, and it is very difficult to deal with. In fact, no cure is known when the 
trouble is well established. It is best to kill any animals which develop paralysis, the trouble being indicated by a lack of ability to control the hind quarters, which are dragged around the hutch.

Diarrhoea and Constipation.-While these ailments are not common, they sometimes occur as a result of feeding too much green stuff after the rabbits have been confined to grain and hay, or from a total lack of such rations. They are easily dealt with. Naturally the amount of green stuff can be reduced when diarrhoea develops, and hot milk may be given. A condition of constipation can usually be remedied by feeding more green stuff.

Skin Troubles and Insects.-There will be little annoyance from these sources if the hutches are kept clean. Sometimes mange develops, and it occasionally happens that vermin infest the coats. The initial step is to clean out all filth and to keep the hutches sanitary and well aired. If the sun can shine into them a part of each day, so much the better. Some kind of mange cure can be tried, and in summer a mixture of sulphur and lard may be applied. 


\section{I52 PRACTICAL RABBIT KEEPING}

Coccidiosis. - Probably much mortality among rabbits for which the owners can find no reason is due to this trouble, which is caused by parasites which are pretty certain to develop wherever there is an accumulation of filth which is not promptly removed. Perfect cleanliness is a certain preventive. One objection to the stacking of hutches in tiers is the increased danger that they will not be kept clean. Urine sometimes seeps through the floors into the hutch below. The reason that rabbits cannot be kept safely for more than a short time in an outdoor yard with an earth bottom is because of the trouble likely to be experienced by the presence of coccidia when the ground becomes foul. 

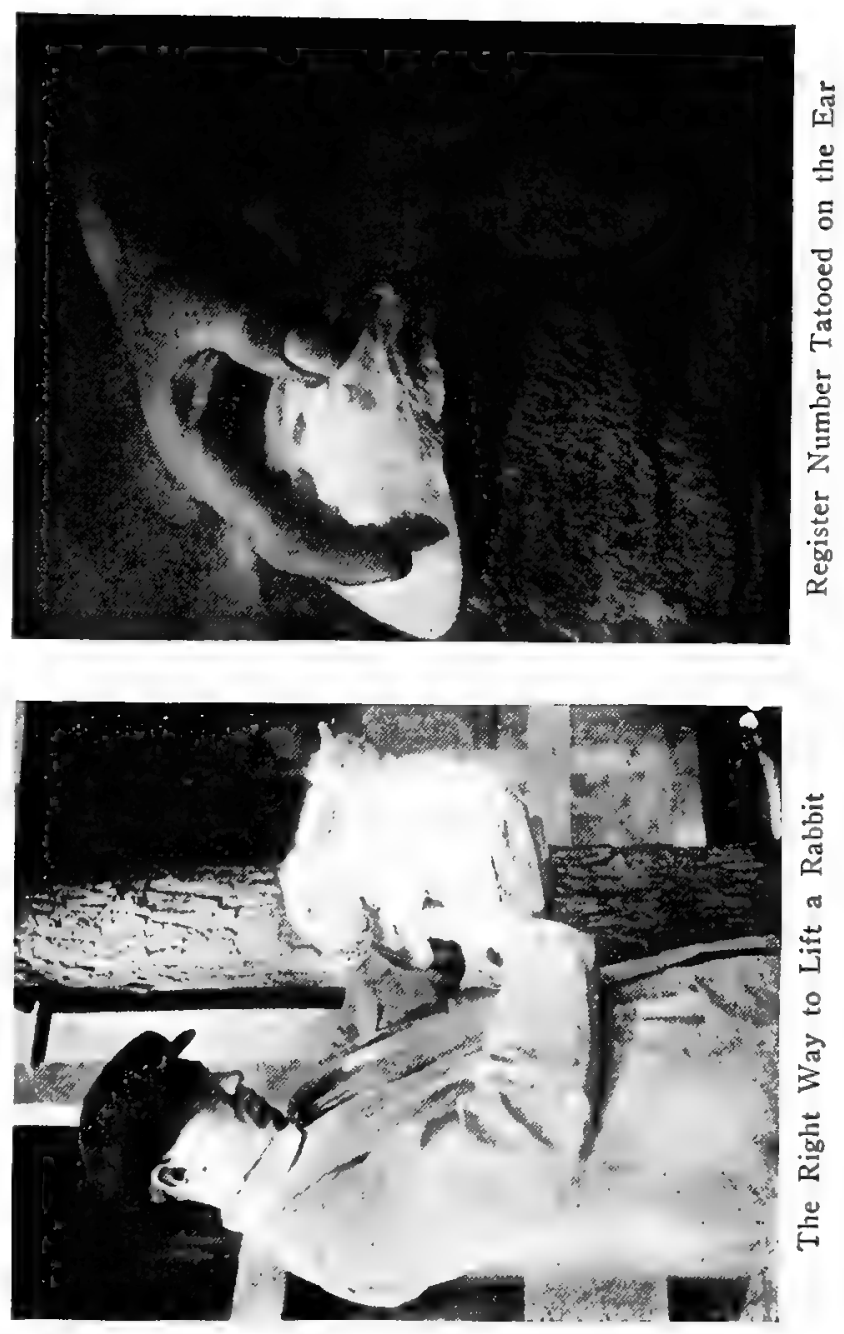



\section{APPENDIX}

RABBIT AND HARE SOCIETY OF CANADA

7 HE rabbit keepers of Canada have an Jrganization which is somewhat differ-

1 ent from the National Association in the United States. It is called the Rabbit and Hare Society of Canada. Its headquarters are at Hamilton, Ontario, and the Secretary and Treasurer, who is also the registrar, is J. E. Peart, of that city.

Animals to be registered are not submitted for examination, but pedigrees in duplicate are sent to the registrar, where, if they are found to be honest and correct, one copy is filed for reference and the other returned to the owner. Sub-societies can be organized in any part of the Dominion, and can hold exhibitions and award prizes by obtaining permission from the supreme society.

The registration fees for Pedigrees are as follows :

I pedigree, 25 cents. 


\section{4 pedigrees, 50 cents.}

Each additional pedigree, ro cents.

When a registered and pedigreed rabbit dies it is the duty of the owner of said dead rabbit to notify the registrar, giving the number of ear tag, name, etc., that a record may be kept for future reference.

Any member of the Rabbit or Hare Society of Canada by sending ro cents in stamps or cash may ask for and receive a copy of any pedigree or other information from the head office.

Any person, either in Canada or the United States, may by sending Five Dollars, and furnishing satisfactory evidence of honesty and fair dealing to the head office, become a member of the Rabbit and Hare Society of Canada, and be entitled to all the rights and privileges it affords.

It is provided that any member of the Rabbit and Hare Society found guilty of misrepresentation of pedigrees or any dishonest dealing in rabbits or hares, shall be expelled from said Society and all the members of the Society shall be notified of such expulsion. 
WEIGHTS OF RABBITS TO BE REGISTERED

At its annual meeting in 1919, the National Breeders' and Fanciers' Association fixed the weights necessary for registration for the various breeds as follows:

Belgian bucks under five and one-half pounds not eligible.

Belgian does under six pounds not eligible.

Flemish bucks under ten pounds not eligible.

White and black bucks under nine pounds not eligible.

Flemish does under eleven pounds not eligible. Black and white does under ten pounds not eligible.

Gray bucks under eleven pounds not eligible.

Gray does under twelve pounds not eligible.

New Zealand bucks under seven pounds not eligible.

New Zealand does under eight pounds not eligible.

Checkered Giant bucks under ten pounds not eligible.

Checkered does under eleven pounds not eligible.

American blue bucks under eight pounds not eligible.

American blue does under nine pounds not eligible. 
Angoras under six pounds not eligible.

Dutch three pounds and over; five pounds and under.

English, three pounds and over; seven pounds and under.

Havanas, over three pounds not eligible.

Himalayan, over two and a half, and under five.

Imperials, over four and under seven.

Polish, under four pounds.

Silver grays, fawns or browns, four to six pounds.

Tans, blacks or blues, three to four pounds.

American blue giants, bucks eight pounds and over; does nine pounds and over.

English Lops, bucks nine pounds; does ten pounds; ears over sixteen inches in length; ears over five inches in width.

A rabbit to qualify for registration should be strong in at least two sections.

The strong and weak points should be specified on the certificate of registration.

\section{LIST OF REGISTRARS}

The following is the list of the registrars in the various parts of the United States, as it existed when this book went to press. Rabbit breeders desiring to have their rabbits registered can send them to the nearest member of 
the board :

Secretary C. H. Gibson, Detroit, Mich.

C. P. Gilmore, Santa Barbara, Cal.

Fred Rose, Grinnell, Iowa.

Rev. George W. Fuller, Florida.

Harry Carter, Tacoma, Washington.

Harry Simon, Indianapolis, Ind.

Louis Griffin, Colorado Springs, Colo.

Reed Storms, Kansas City, Mo.

F. C. Fairchild, Wichita, Kans.

R. A. Baird, Oklahoma City, Okla.

W. B. Campbell, Denver, Colo.

Homer Sanderson, Eagle Rock, Cal.

Wm. Yerkes, Houston, Texas.

Percy Rowland, Newcastle, Pa.

Jesse McCullough, North Louisburg, Ohio.

H. L. Thomas, Waco, Texas.

Boyd, Polk, Ohio.

H. J. Plegge, St. Louis, Mo.

Glen Barbour, Chelsea, Mich.

John Fehr, Indianapolis, Ind.

J. M. Gibson, West Alexander, Pa.

Geo. Nugent, San' José, Cal.

J. Needham, Seattle, Wash.

L. L. Whitmore, Akron, Ohio.

Oscar Hull, Tacoma, Wash.

H. C. Brown, Emporia, Kans.

A. E. Chapman, Topeka, Kans.

C. C. Hawley, Dallas, Texas.

F. A. Wilke, Boise, Idaho. 
Louis Salisbury, Pasadena, Cal.

R. F. Foulke, Waynesboro, Pa.

T. P. Thompson, Harrisburg, Ill.

C. P. Denlea, Brooklyn, N. Y.

Edward Condon, Chicago, Ill.

George Eckert, Chicago, Ill.

A. G. Prather, Ukiah, Cal.

C. R. Pinneo, Omaha, Neb.

Frank Harris, Des Moines, Iowa.

W. H. Ashton, Dayton, Ohio.

F. C. Fidler, Syracuse.

Geo. E. Hilton, Oakland, Cal.

Andrew Wilson, Los Angeles, Cal.

R. E. Cushman, Sterling, Ill.

Ignatz Gruber, Fort Wayne, Ind.

G. W. Abbott, Newtonville, Mass.

A. M. Lewis, Terre Haute, Ind.

Ernest Haarer, Ann Arbor, Mich.

C. E. Church, Charlotte, Mich.

Farley, Birmingham, Ala.

Ernest Gernslager, Murphyșboro, Ill.

Saylor, Cedar Rapids, Iowa.

Stegena, Grand Rapids, Mich.

H. M. Adolph, Cleveland, Ohio, Chairman.

\section{GRIEVANCE COMMITTEE}

The grievance committee of the National Breeders' and Fanciers' Association was estab- 
lished to obviate unfair dealings, particularly between buyers and sellers. The chairman is H. N. Adolph, of 423 I Mapledale Avenue, Cleveland, Ohio. The other members of the committee are George W. Abbott, Newtonville, Massachusetts; R. C. Cushman, Sterling, Illinois; J. D. Lane, 2839 Terrace Avenue, Kansas City, Kansas; George W. Hilton, 36 i 5 Penniman Avenue, Oakland, California. All complaints should be made to the nearest member of the committee. In all mail transactions, it is wise to save the envelopes which help to obtain redress and enlist the assistance of the federal authorities. Any member of the National Association can take advantage of the opportunity offered by the grievance committee.

\section{BREEDING RECORDS}

It is necessary to keep careful records when breeding rabbits. Below is a sample record. It can be obtained printed on cardboard, size $3 \times 6$, at the rate of one cent each, from supply . houses. 


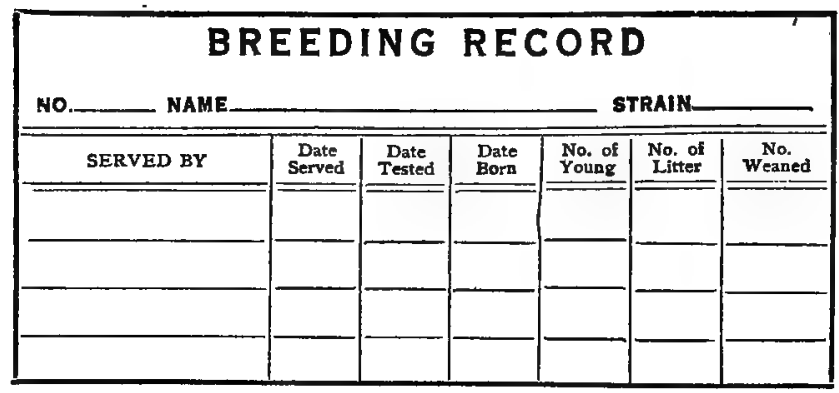

WHAT LOP EAR IS

Amateur rabbit keepers are often puzzled by a condition known as lop ear in which one and sometimes both ears of the rabbit hang down to one side and seem beyond the rabbit's control. It is usually caused by hot weather or by very close confinement. It is, of course, a disqualification and bars the animal from the show room. Naturally this does not apply to the lop-eared breeds.

\section{DEWLAP}

The dewlap is a peculiar growth which may appear under the chin of Belgian hares, Flemish Giants and New Zealand Reds. Breeders 
are trying to eliminate it and it occasions a cut in the score when rabbits are being exhibited. The presence of a dewlap, however, does not disqualify the rabbit for entrance unless it is unusually large. In breeding to get rid of the dewlap, bucks free from dewlap should be used. The dewlap itself is a development of glands and is accentuated in does by frequent breeding.

\section{MARKING RABBITS}

The only possible way to keep track of pedigreed rabbits when they are being bred on anything but a very small scale is to mark or tag each individual. There are two ways of doing this. One is to punch the ear and insert a metal tag carrying a number and kept from slipping out by means of a washer. The other way is to tattoo a number on the inside of the ear. This is done with a special instrument obtained from the supply houses and indelible ink. Each plan has its supporters. Of course it is necessary to tag or mark the rabbits when they are very young, or there is danger that they will become mixed with other animals 
and their identification will be impossible.

\section{RABBIT KEEPING LITERATURE}

With the greatly increased interest in rabbit keeping which has developed in the past few years has come a corresponding increase in rabbit literature. There are several periodicals devoted to rabbits and other small stock. The list includes the following:

Rabbit Craft and Small Stock Journal, American Breeders' Review, I32 Nassau Street, New York City; 50 cents a year.

The National Breeders' and Fanciers' Magazine, 335 Southeast Avenue, Oak Park, Illinois, monthly, subscription, $\$ 1.00$ a year.

Rabbit Craft and Small Stock Journal, Lamoni, Iowa, monthly, subscription, 50 cents.

Outdoor Enterprises and Domestic Pets, 408 Admiral Boulevarde, Kansas City, Missouri, monthly, subscription, \$1.00.

American Breeders' Review, 132 Nassau Street, New York City; 50 cents a year.

Hares and Rabbits, Greenfield, Indiana, monthly, subscription, \$I.00. 
There are few books among those published. in America devoted wholly to rabbits except those issued by breeders. The books most commonly quoted are the following:

"Breeding and Care of Rabbits," by Charles: S. Gibson, published by Charles S. Gibson, ro45 West Warren Avenue, Detroit, Michigan.

"Rabbit and Cavy Culture," by W. F. Roth and Charles T. Cornman, published by Item Publishing Company, Sellersville, Pennsylvania.

"Rabbit Breeders' Ready Reference," O. K. Poultry Journal Co., Mounds, Oklahoma.

Other books are: "Commercial Rabbit. Farming," published by Outdoor Enterprise: Company, Kansas City, Missouri; "Richey's Western Rabbit and Cavy Book," published. by the Monrovia Publishing Company, Monrovia, California; "Raising Rabbits Right," published by the Pet Stock World, Baltimore, Maryland. A brief but excellent bulletin. entitled "Raising Belgian Hares and Other Rabbits" is issued by the United States Department of agriculture at Washington, from which it may be obtained without charge by 
164 APPENDIX

writing for Farmer's Bulletin Number 496. THE STANDARDS OF PERFECTION

There is only one way to establish uniformity in any breed of animals, and that is for those who breed them to unite upon certain characteristics and color markings as the ideal to strive for. If this plan were not followed, all breeders would be working along different lines and nothing could be accomplished. There are organizations to foster the breeding of all the leading breeds of rabbits. These organizations are responsible largely for the ideals which are determined upon, and which constitute what are called the standards of perfection. It is to be understood, of course, that a rabbit which is one hundred per cent perfect is not to be found in any breed. The ideal is always kept a little ahead of what has been achieved; but with the standard to guide them a remarkable uniformity is obtained by expert breeders. As fast as new breeds are created and become popular, a standard is fixed for them. In each case the standard goes specifically into details covering weight, color markings, general conformation, and the like. By 


\section{APPENDIX}

studying them, the amateur will be able to judge the quality of the animals which he owns, and to shape his plans in an effort to improve his stock. The revised standard of perfection has not been completed as this book goes to press but can be obtained as soon as published from the Secretary of the National Association, Charles S. Gibson, I05 W. WWarren 'Avenue, Detroit, Michigan. 


\section{INDEX}

\section{A}

Advertising, 50, 115

Ailments, how to treat, 146 American Spotted Giants, 14,29

Angoras, 15, 37

Argent de Champagne, 11

$\mathrm{B}$

Belgian dares, 1, 9, 12, 42, 47 color of, 25 shape of, 26

Black Siberian Hares, 28

Blue Imperial Rabbits, color of, 40

Bread and milk for does, 91 Breeding, age for, 98

best seasons for, 99

fancy stock, 116

how to induce, 100

methods outlined, 101

records, 159

stock, age of, 100

Breeds,

American Spotted Giants, 14

Angoras, 15, 37

Argent de Champagne, 11

Blue Imperials, 40

Dutch, 14, 31, 42

English, 13, 30
Flemish Giants, 13, 17

Giants, 27, 49

Himalayans, 13, 33, 43

Lop-eared, 10, 15, 32

New Zealand Reds, 15, 17, $34,42,47$

Polish, 35

Silver Blues, 39

Silver Browns, 39

Silver Fawns, 39

Silver Grays, 38

Tans, 40

C

Cabbages, value of, 82

California, Rabbits in, 5, 18

Canada; Rabbit and Hare Society of, 153

Canning rabbit meat, 131

Carrots, food value of, 83

Children, rabbits for, 41

Common rabbits, 41

Cooking fabbits, 130

Cost of raising rabbits, 3

\section{$\mathrm{D}$}

Demand for rabbits, 4

Dewlap, nature of, 160

Dogs, danger from, 76

Dressing rabbits, 128

Dutch rabbits, 14, 31, 42 


\section{INDEX}

II

English rabbits, 13, 30

Europe, rabbits in, 11

Exhibiting, pleasures of, 115

Exhibitions, 24

preparing for, 116

\section{$\mathbf{F}$}

Fancy rabbits, 6, 10, 12 breeding, 116

Farms, rabbit, 23

Feeding green stuff, 81 pregnant does, 91, 94 young rabbits, 44, 81, 92

Fighting, how to prevent, 78 Flemish Giants, 13, 17

Foundation stock, importanco of, 116

Fur, 11

making garments from, 140

sources of, 136

uses of, 138

value of, 137

\section{G}

Giant rabbits, 26

American Spotted,29

Black Flemish, 28

Black Siberian, 28

crosses of, 49, 98

Gray Flemish, 27

Steel Gray Flemish, 27

White, 28

Grain, amount required, 93

variety in, 90
Grievance Committee, 158

\section{H}

Hares, 9, 25

Hay, amount required, 93 character of, 91

Healthy rabbits, how to know, 52

Himalayan rabbits, 13, 33, 44

History of the breeds, 9

Hutches, character of, 55

for young stock, 72

indoor, 58

movable, 59

nest boxes in, 63

outdoor, 59, 66

self-cleaning, 60

size of, 56

I

In-breeding, meaning of, 106 result of, 108

K

Kale, curly Scotch, 87

L

Lifting rabbits, manner of, 77

Line-breeding, manner of, 107

Literature of rabbit keeping, 162

Litters, number of per year,

96

size of, 104

Lop ear, cause of, 162

Lop-eared rabbits, 10

English, 32

French, 15 


\section{M}

Marking, methods of, 161

Meat rabbits, 2, 22

age of, 127

demand for, 126 .

how to dress, 128

how to market, 129

Morant system, the, 69

$\mathrm{N}$

National Breeders' and Fan. ciers' Association, 155

Nest boxes, 63, 102

New Zealand Red Rabbits,15, $17,34,42,47$

color of, 35

New Zealand spinach for fall feeding, 88

\section{0}

Over-feeding, danger of, 94 $\mathbf{P}$

Parsnips, food value of, 84

Pedigrees, how made, 122

Pelts, how to cure, 143

how to remove, 141

Pet rabbits, 7, 41

Polish rabbits, 35

grooming for exhibition, 117

Potatoes, food value of, 88

Pot belly, cause of, 92

how to prevent, 150

Prices for average stock, 48

Purchasing stock, 51

by mail, 52

rules for, 123
R

Rape for spring feeding, 87

Recipes, 131

Registering, cost of, 121

value of, 120

Registrars, list of, 156

Registration, rates for, 153

$\mathbf{S}$

Salt. amount of, 94

Sanitation, how to secure, 75 need of, 75

Sex, how to determine, 53

Shipping, boxes for, 118

Silver Blues, 39

Silver Browns, 39

Silver Fawns, 39

Silver Grays, 38

Standards, 164

Stud book, necessity for, 106

Sunlight, protection from, 76

\section{T}

Table scraps, value of, 92

Tans, Black and, 40

$\mathrm{V}$

Vegetables, how to feed, 88 raising, 83

storing, 85

\section{W}

Water needed daily, 94 receptacles for, 94

Witloof ehicory, how to force, 85

\section{$\mathbf{Y}$}

Yards, dog-proof 68

with floors, 71 



